Linköping Studies in Science and Technology,

Thesis No. 1702

\title{
Time Correlated Single Photon Spectroscopy on Pyramidal Quantum Dots
}

Tomas Jemsson

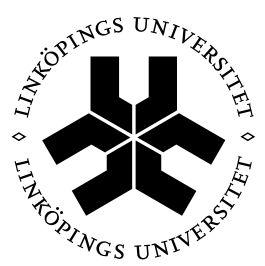

Linköping University INSTITUTE OF TECHNOLOGY

Semiconductor Materials Division

Department of Physics, Chemistry and Biology (IFM)

SE-581 83Linköping, Sweden 
ISBN: 978-91-7519-143-0

ISSN 02807971 


\section{Abstract}

Generation of non-classical light is both of fundamental interest and a common condition for quantum information applications (QIA). One feasible type of single photon emitter for QIA is based on semiconductor quantum dots (QDs), due to their atomic-like energy structure and their possibility to be integrated with other semiconductor devices on the same chip. Sitecontrolled QDs with highly linear polarized emission are a prerequisite for certain QIA and a close to room temperature operation is demanded for widespread applications.

III-nitride QD can have the deep confinement potentials needed for high temperature operation, and the demonstration of single photon emission at room temperature was recently reported for a GaN QD [Nano Lett. 14, 982 (2014)]. Asymmetric III-nitride QD emits light with a high degree of linear polarization. To make site-controlled nitride-based QDs a promising approach is to deposit a thin layer of InGaN on top of hexagonal GaN micropyramids. QDs formed on the apex of the pyramids grown with this approach have been shown to exhibit single and sharp InGaN related emission lines with a high degree of linear polarization [Nano Lett. 11, 2415 (2011)]. A simple elongation of the pyramid base gives control of the polarization direction [Light: Sci. Appl. 3, e139 (2014)].

The work presented in this thesis deals with time correlation measurements, to measure, for the first time, the single photon properties of these pyramidal QDs.

A time correlated single photon spectroscopy (TCSPS) setup was assembled, tested and used to perform measurements on these pyramidal QDs. The TCSPS apparatus measures the time differences $\tau$ between subsequent photons emitted from the sample. In the spectrally filtered light of one emission line in the emission spectra, e.g. exciton emission, of a QD two or more photons cannot be emitted simultaneously, i.e. the photons are sent out one by one. A histogram of the ensemble of measured time differences $\left(\sim 10^{6}\right.$ events) will then for the ideal case have no events for $\tau=0$, and very few for $\tau$ close to zero. This histogram, when normalized, is under certain conditions equal to the second order coherence function $g^{(2)}(\tau)$. In reality, however, there are photons coming from other sources close to the QD, i.e. background emission, that reach the detector and reduce the dip in the correlation histogram for small $\tau$. There is also an statistical uncertainty in the measured time differences and finally the finite bin width used in the histogram that 
deteriorate the measured correlation function. To understand the influence on $g^{(2)}(\tau)$ from background emission, instrument response function and the bin width, on the measurement on excitonic emission, simulations and calculations were made. The crucial variables were, for our samples and setup, the level of the background emission and the instrument response function.

A post growth process was developed to cover the lower parts of the pyramid sides as well as the area between the pyramids with a metal film, to reduce the background emission. This reduces the background emission and largely improves the relative QD signal. As a result, significant improved single photon characteristics were demonstrated.

A measurement of the second order coherence function for the excitonic autocorrelation at a temperature of $12 \mathrm{~K}$, gave for zero time delay $(\tau=0)$ a value of $g^{(2)}(0)=0.24$ and the residual value of the second order coherence function (0.24) could be in full explained by the three variables, background emission, instrument response function and bin width. The $g^{(2)}(0)$ value for correlation measurements at higher temperatures of $50 \mathrm{~K}$ and $80 \mathrm{~K}$ is also fully explained by the three variables, showing that the emission from the QD itself is ideal up to $80 \mathrm{~K}$.

This result underlines the great potential of these site controlled pyramidal dots as sources of fast polarized single photon emission, and provides the first rigorous evidence of InGaN quantum dot formation on hexagonal GaN pyramids. We also show the first proof of biexcitonic emission in this pyramidal QDs. 


\section{Preface}

This thesis work has been done within the framework of the Swedish national graduate school in science, technology and mathematics education research (fontD). All of the work was performed within the Semiconductor Materials Division at the Department of Physics, Chemistry and Biology at Linköping University between March 2012 and January 2015.

The thesis is divided into two parts where the first gives an introduction to the topics essential for the thesis work; semiconductors, quantum dots, photoluminescence and correlation spectroscopy. The second part consists of a collection of the following papers.

\section{Paper I.}

Linearly polarized single photon antibunching from a site-controlled InGaN quantum dot.

Tomas Jemsson, Houssaine Machhadani, K. Fredrik Karlsson, Chih-Wei Hsu, and Per-Olof Holtz,

APPLIED PHYSICS LETTERS 105, 081901 (2014)

\section{Paper II.}

Polarized single photon emission and photon bunching from an InGaN quantum dot on a GaN micropyramid.

Tomas Jemsson, Houssaine Machhadani, K. Fredrik Karlsson and Per-Olof Holtz,

NANOTECHNOLOGY accepted for publication

\section{Conference contributions not included in the thesis.}

\section{I.}

InGaN quantum dots grown on ordered GaN micropyramids.

K. F. Karlsson (invited), A. Lundskog, C. W. Hsu, S. Amloy, U. Forsberg, T. Jemsson, H. Machhadani, E. Janzén and P. O. Holtz.

Invited talk, the 10th international workshop on Epitaxial Semiconductors On Patterned Substrates And Novel Index Surface (ESPS-NIS 2014), Traunkirchen, Aus- 
tria, June 20-23 (2014).

\section{II.}

InGaN quantum dots as source of single photons.

H. Machhadani, T. Jemsson, K.F. Karlsson, C.W. Hsu , and P.O. Holtz Poster Presentation,

10th International Symposium on Semiconductor Light Emitting Devices (ISSLED 2014), Kaohsiung, Taiwan, Dec 15-19 (2014).

\section{III.}

Toward the realization of an electrically driven source of polarized single photons.

Houssaine Machhadani, Tomas Jemsson, Fredrik Karlsson, Per Olof Holtz Oral Presentation, the 4th Sweden-South Africa Workshop (Linköping - Port Elizabeth/Bloemfontain), Karlskrona, Sweden, June 15-18 (2014).

IV.

Toward the realization of an electrically driven source of polarized single photons.

Houssaine Machhadani, Tomas Jemsson, Fredrik Karlsson, Per Olof Holtz Oral Presentation, the 10th Micronano System Workshop, Uppsala, Sweden, May 15-16 (2014) 


\section{Acknowledgements}

I would like to thank:

My supervisor Associate Professor Fredrik Karlsson, for introducing me to an interesting subject and for his endless support and for sharing his vast knowledge with me.

My assistant supervisor Professor Per-Olof Holtz, for giving me the opportunity to do this thesis and for encouragement and support, but also for organizing social activities like the regular sub division lunches. We had always nice discussions, and fellowship.

Houssaine for those seemingly endless days aligning the setup, for making nice figures and for your positive attitude. I liked the conversations on much about everything while eating our lunch boxes.

Martin for nice discussions, and for always finding what I was looking for in the lab.

Abdel for conversation during the hours in darkness, while measuring on our different setups. The time passed on faster.

Chih-Wei for his nice smile and for teaching me the basic structure of Chinese.

Dao, Daniel for fellowship at the lunches. Roger Calmesten for keeping the Helium bottles full. Eva Wibom for taking care of administrative matters. Former and present colleagues at Physics department, Finnvedens Gymnasium for cooperation, nice coffee breaks, and the quite frequent morning monolog, I have truly missed them.

I want to thank my head master at Finnvedens Gymnasium, Värnamo, Kerstin Brandt, who encouraged me to apply to the Licentiate program at Fontd and has been very supportive in various ways including organizing my lesson schedule in the best way possible.

I also want to thank my Mother and Father in law, Irene and Nisse Johansson, for accommodation and good food, including the lunch boxes with the content neatly written on the lid. It was not easy for you to know at what time I should arrive at your home, usually it was late.

Finally and foremost I want to thank my family. My wife Monica and our kids Axel, Linnéa and Oscar for endless support, and patience during this years, especially during the last months. I owe you all much, I know. 


\section{Contents}

1 Background 1

2 Introduction to semiconductors 3

2.1 What is a semiconductor? . . . . . . . . . . 3

2.2 The wurtzite crystal structure . . . . . . . . . . 5

2.2 .1 Reciprocal space . . . . . . . . . . . . . . 6

2.3 Electronic structure . . . . . . . . . . . . . . . . . . 7

2.4 Optical properties of semiconductors f . . . . . . . 7

2.5 Quantum dots . . . . . . . . . . . . . . . . 9

2.6 Excitonic complexes . . . . . . . . . . . . . . . . 10

2.7 Fabrication of quantum dots . . . . . . . . . . . . . 11

3 Photoluminescence spectroscopy 13

3.1 Photoluminescence spectroscopy . . . . . . . . . . . . . . . 13

3.1.1 Micro-photoluminescence spectroscopy . . . . . . . . . 14

3.1.2 Time resolved $\mu$ PL-spectroscopy . . . . . . . . . . . 16

3.1.3 Polarized $\mu$ PL-spectroscopy . . . . . . . . . . . . 16

3.2 Apparatus . . . . . . . . . . . . . . . . 17

3.2 .1 Excitation sources . . . . . . . . . . . . 17

3.2 .2 Objectives . . . . . . . . . . . . . . . 17

3.2 .3 Cryostat . . . . . . . . . . . . . . . . 17

3.2 .4 Detectors . . . . . . . . . . . . . . . 17

3.2 .5 Filters . . . . . . . . . . . . . . . 18

4 Time correlated single photon spectroscopy 19

4.1 Introduction . . . . . . . . . . . . . . . . . . . 19

4.1 .1 Theoretical basis . . . . . . . . . . . . . 20

4.1 .2 TCSPS measurements . . . . . . . . . . . . . 21 
4.1.3 Quantum dots as emitters of correlated photons . . . . 23

4.2 Continuous laser mode . . . . . . . . . . . . . . . . . 24

4.3 Pulsed laser mode . . . . . . . . . . . . . . . . . 26

4.4 Apparatus . . . . . . . . . . . . . . . . . . . . . . 28

4.4 .1 Detectors . . . . . . . . . . . . . . . . . . . 28

4.4 .2 Instrument time response . . . . . . . . . . . . . . 29

5 Simulation of TCSPS histograms:

effects of experimental non-ideality $\quad 31$

5.1 Method ....................... 31

5.2 Simulated effect of background emission . . . . . . . . 32

5.3 Simulated effect of instrument time response . . . . . . . . . . 33

5.4 Simulated effect of histogram bin width . . . . . . . . . . 34

5.5 Combined effect of $b w, \tau_{i}$ and $\rho$ on the $g^{(2)}(0)$-value . . . . 35

6 Bibliography 37

$\begin{array}{ll}\text { Papers } & 41\end{array}$ 


\section{Chapter 1}

\section{Background}

The work of Maxwell in the middle of the nineteenth century unifying electromagnetism in just four relatively simple equations was a landmark showing the progress physicists had made. There started to be a feeling that science soon was complete, it cannot be so much more to discover. Therefore it is told that professors in Germany did not recommend students to be a physicist simply because there was not much left to explore [1]. It turned out that some of those remaining problems e.g. black body radiation, the stability of the atom and the photoelectric effect, gave rise to a new field of physics, quantum mechanics. Quantum mechanics has been a paradigm in understanding atoms and their interactions using wave functions and introducing a probabilistic approach. The quantum mechanics has together with novel growth methods and pure materials made it possible to understand semiconductor materials and develop semiconductor devices that have become the backbone of our everyday world. There are many materials that are semiconducting, both from group IV and combinations from group III-V and also from group II-VI in the periodic table [2].

The nitrides from group III (Al, In, Ga) are one of those material systems that already at the end of the 1950s where seen as the basis of a new possible lighting technology when photoluminescence from GaN was shown [3]. By making a ternary alloy with two of the three group III-metals together with nitrogen, light emitting diodes (LED) should be possible to make with photon energies ranging from UV to IR [4]. However the quality of the GaN crystals was poor and it was not until 1986 that GaN could be produced with high crystal quality [5]. Almost a decade later, in 1994, the first LED emitting in blue from the III-nitrides was made [6]. 
For conventional lightning purpose the blue LEDs are covered with a phosphor so that the blue light is converted to white light. Theses white light LEDs are $\sim 20$ times more energy efficient compared to light bulbs. The invention of efficient blue light-emitting diodes which has enabled bright and energy-saving white light sources was awarded with the Noble Price in Physics 2014 [7].

The blue LEDs are made of a embedded two dimensional structure, like a thin film, where the charge carriers (electrons and holes) are localized on opposite sides of the film. For sufficiently thin films, there is a strong localization of the carriers that gives an increased efficiency in the light production. Other low dimensional semiconductor structures like one dimensional rods or even zero dimensional points have an even stronger localization of charges. The zero dimensional structures, the point, is called a quantum dot (QD) and has some special features. A QD can be a single photon emitter which means that it can not send out two or more photons with the same energy simultaneously [8]. QDs of InGaN send out highly linearly polarized photons, i.e. photons that have the same constant electrical field vectors. The idea to fabricate this InGaN QDs on top of an elongated base GaN pyramid has been successful in terms of making the QD site controlled but also in pre-destinating the direction of the polarized emission. A potential use of these special properties is in optical communication lines where an unbreakable chiefer could be made by using linearly polarized photons emitted in two perpendicular directions one by one $[9,10]$.

The unambiguous way to test the single photon properties of a QD is by time correlated single photon spectroscopy (TCSPS), i.e. a measurement method where the time difference between the emissions of subsequent photons are measured [11].

The scope of the work leading to this thesis was to assemble and test a TCSPS apparatus and to use it mainly in investigating the single photon properties of InGaN pyramidal QDs emitting in the UV spectral range. 


\section{Chapter 2}

\section{Introduction to semiconductors}

\subsection{What is a semiconductor?}

In an atom, the energy levels are discrete (figure 2.1a). An experimental proof for this is shown in many high schools, where a rarefied gas is exposed to a high voltage spark giving electrons enough energy to be excited to a higher energy level. When the electrons subsequently relax back to the ground state the excess energy is sent out as a photon of single frequency. The photon energy is given by the energy difference between the initial and final state and are characteristic for the atom type. When the individual atoms are brought closer to each other, the energy levels split up and continuous energy bands are formed when the individual atoms are merged into a crystal (figure 2.1b). Between the energy bands, there could be energy gaps, where there are no energy levels, these are referred to as band gaps. The labels $\mathrm{s}$ and $\mathrm{p}$ in figure $2.1 \mathrm{~b}$ refers to the spherical symmetric s-levels of an atom and the plevels are directed in three perpendicular directions $\left(\mathrm{p}_{x}, \mathrm{p}_{y}, \mathrm{p}_{z}\right)$ as learned in atom physics.

In metals the highest band that is occupied with electrons, the valence band (VB), is not completely filled and the electrons are free to move.

At thermodynamic equilibrium, the distribution function for electrons (fermions) is given by the Fermi-Dirac distribution $f_{e}(E)$

$$
f_{e}(E)=\frac{1}{\exp \left(\frac{E-E_{F}}{k_{B} T}\right)+1},
$$

where $E_{F}$ is the Fermi level, $k_{B}$ is Boltzmanns constant and $T$ is the tem- 

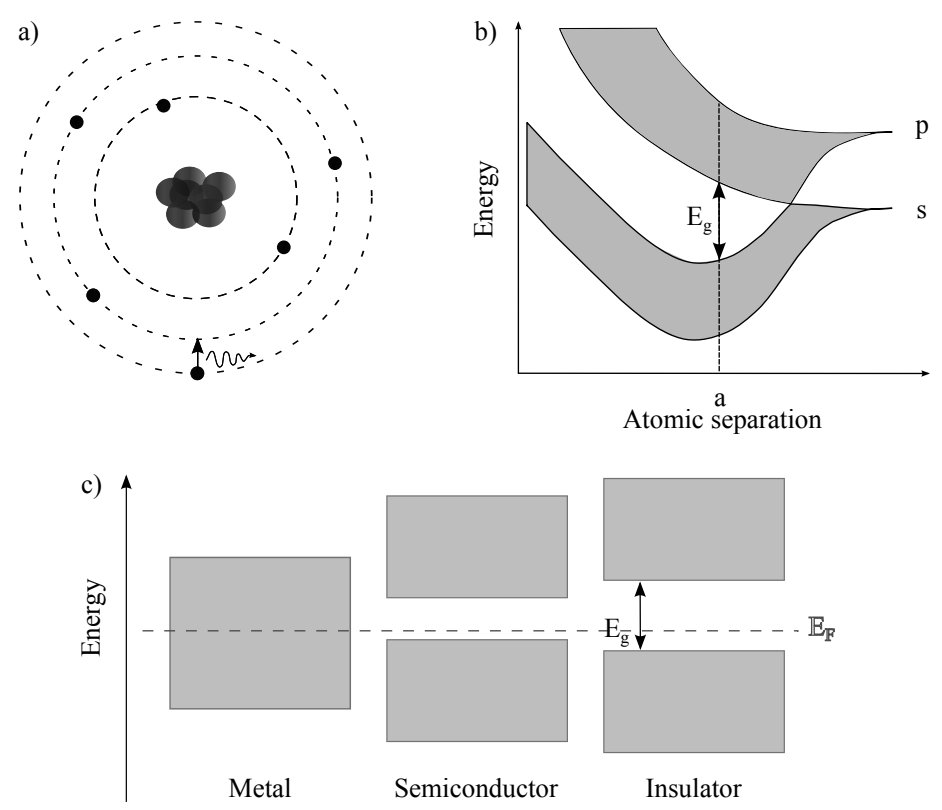

Figure 2.1: a) A schematic illustration of the Bohr model for the atom. b) The transition into energy bands in a crystal. c) A schematic illustration of the level of the Fermi level $\left(E_{F}\right)$ in a metal, semiconductor and an insulator.

perature. $f_{e}(E)$ may be interpreted as the probability of the energy level of energy $E$ being occupied. The Fermi level is defined as the energy where the probability of a energy level being occupied is $\frac{1}{2}$ i.e. $f_{e}\left(E_{F}\right)=\frac{1}{2}$. For metals $E_{F}$ are in the VB (figure 2.1c). In a semiconductor, the VB is completely filled at absolute zero temperature and there is a band gap $\left(E_{g}\right)$ up to the next band, the conduction band $(\mathrm{CB})$, that is empty. With a filled band there are no empty levels and therefore no net-current from electrons and subsequently very low electrical conductivity. At room temperature, a fraction (larger fraction for a small band gap) of electrons have gained enough thermal energy to be lifted up to the $\mathrm{CB}$, and the conduction increases. For an insulator the band gap is too large, the thermal energy provided at reasonable temperatures are not sufficient to promte electrons to the CB. The band gaps, at room temperature, for the semiconductor materials used for this investigation are $0.7 \mathrm{eV}$ for $\mathrm{InN}$ and $3.4 \mathrm{eV}$ for $\mathrm{GaN}[12,13]$. 
The electrons in the $\mathrm{CB}$ leave unoccupied states in the VB referred to as holes. A valence band hole acts like a positively charged particle and can be assigned physical properties like momentum and mass. Both the free electrons in the $\mathrm{CB}$ and the free holes in the VB take part in the conductivity. Electrons and holes are both called charge carriers. An electron in the CB can recombine with a hole in the VB and emit a photon, like an excited atom. The energy of the emitted photon is characterized by the band gap of the semiconducting material.

The upper edge of the VB originates from the p-type energy levels (fig. 2.1b) and the bottom edge of the $\mathrm{CB}$ originates from the s-type energy levels. These band edges are interesting because there are most often involved in optical transitions.

\subsection{The wurtzite crystal structure}

a)

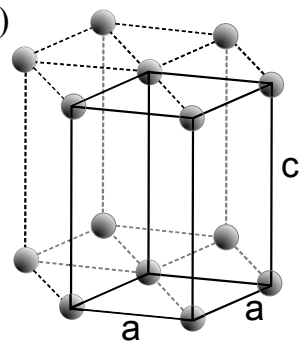

b)

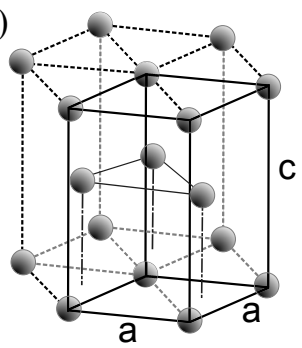

c)

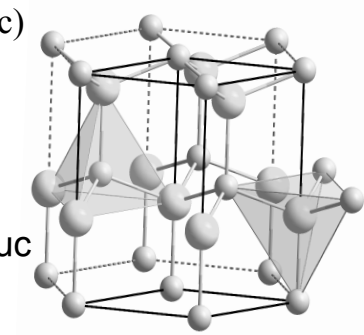

Figure 2.2: Crystal structures a) simple hexagonal b) hexagonal close packed and c) wurtzite structure. A conventional cell of each structure is highlighted by black solid lines.

The ternary alloys of GaN and InN, can crystallize in the zinc-blende or preferentially in the wurtzite structure [14]. The samples used in this study where all crystallized in the wurtzite structure. To illustrate the wurtzite structure, we first consider the simple hexagonal lattice. This lattice could be seen as plane nets of equilateral triangles with side length $a$ and with a lattice point in each corner of the triangles, the perpendicular distance between the nets is $c$ (figure 2.2a). If we introduce a new equilateral triangular net at $c / 2$ translated so that the projection of the lattice cites in the $c$-direction are 
Table 2.1: Structural parameters of wurtzite GaN and $\mathrm{InN}$ at $300 \mathrm{~K}$, compared to an ideal wurtzite structure.[15]

\begin{tabular}{r|ccccc} 
& $a(n m)$ & $c(n m)$ & $c / a$ & $u$ & $u c(n m)$ \\
\hline GaN & 0.3189 & 0.5185 & 1.626 & 0.376 & 0.195 \\
InN & 0.354 & 0.5705 & 1.612 & 0.377 & 0.215 \\
'ideal' & & & 1.633 & 0.375 & \\
\hline
\end{tabular}

in the middle of the equilateral triangles in the simple hexagonal structure in figure 2.2a, we have made a hexagonal close packed (hcp) structure (figure 2.2b). Two hcp structures distanced $u \cdot c$ apart in the $c$ direction, [0001], one containing the $\mathrm{N}$-atoms and the other the $\mathrm{Ga}(\mathrm{In})$-atoms together build up the wurtzite structure (figure 2.2c) with one atom at each lattice site. The unit cell of hcp contains two lattice sites and accordingly the unit cell of the wurtzite holds four lattice sites, two from each hcp lattice. The values of $a, c$ and the internal parameter $u$, defined as the bond length $\mathrm{Ga}(\mathrm{In})-\mathrm{N}$ divided by the $c$ lattice constant, is given in table 2.1 .

The tetrahedrals formed by the $s p^{3}$ hybrid bonds (linear combinations of the atomic s and p orbitals) in InGaN have a more ionic character compared to other III-V semiconductors, dependent on $\mathrm{N}$ being the most electronegative element in group $\mathrm{V}$, thus attracting negative charges more efficiently. Also, the angle between the [0001] oriented $\mathrm{Ga}(\mathrm{In})-\mathrm{N}$ bond and any other $\mathrm{Ga}(\mathrm{In}) \mathrm{-N}$ bond in the tetrahedron is slightly less than the ideal value of 109.5 . Therefor, a polarization occurs in the material along [0001]. The sum of all dipole moments will have the effect of a capacitor like charge separation between the top and bottom (0001) planes of the crystal, resulting in an intrinsic internal electric field. An electric field that could be enlarged if the crystal is under stress, which often is the case in heterostructures [16].

\subsubsection{Reciprocal space}

A space lattice is a periodic function of real space and any periodic function $f(r)=f(r+R)$, where $R$ is a vector connecting any two points in the crystal lattice, can be expanded by a Fourier transform as

$$
f(r)=\sum_{k} A_{k} \cdot e^{i k . r}
$$


where the summation $k$ is over a discrete set of vectors $\mathrm{G}$. While the reciprocal space is the space, in which the Fourier transform of a spatial function is represented the $\mathrm{G}$ vectors, define points in reciprocal space ( $k$-space) with a periodic structure. The reciprocal lattice is defined by $\mathrm{G}$.

The simple hexagonal crystal lattice which in reciprocal space also is a simple hexagonal lattice rotated $30^{\circ}$ around the c-axis. Accordingly the reciprocal to the wurtzite structure is a simple hexagonal lattice with a four atom form factor.

\section{$2.3 \quad$ Electronic structure}

For a free electron, the electron energy is $E(k)=\frac{\hbar^{2} k^{2}}{2 m_{0}}$ where $\hbar$ is the reduced Planck constant, $k$ is the wave vector and $m_{0}$ is the free electron mass. In the materials considered an electron close to the band edge have a parabolic $E(k)$ dependence similar to the free electron model but the curvature is different, which is corrected for by introducing an effective mass $m^{*}$. The holes could be associated with a negative effective mass and a $k$ vector of opposite direction with respect to the unoccupied electron state $k_{e}=-k_{h}$. The origin of the valence band from the atomic $\mathrm{p}$ orbitals gives a threefold splitting of the hole parabolas, which conventionally are labeled A, B and C with increasing energy (in the hole picture). The effective masses are anisotropic i.e. $m^{*}$ have different values in different directions, unlike the free electrons. The $E(k)$ dispersion for small $k$ bands for different effective masses $m^{*}$ of the electron and the hole $\mathrm{A}, \mathrm{B}$ and $\mathrm{C}$ band, in $k_{x}$ and $k_{z}$ directions are seen in figure 2.3. The figure represent a small part of the band structure in reciprocal space around the $\Gamma$ point $(k=0)$.

Semiconductor materials have a spectrum of allowed electronic states. The number of states for a certain energy, called the density of states $\left(\rho_{D O S}\right)$, is for bulk materials proportional to $\rho_{D O S}^{3 D} \propto \sqrt{E}$. The bulk $\rho_{D O S}^{3 D}$ is a continuous function with $E$.

\subsection{Optical properties of semiconductors}

The optical properties refers to the material response of exposure to electromagnetic radiation of wavelengths in the visible or close to visible spectral range. The electromagnetic radiation with energy $E$ may excite electrons 


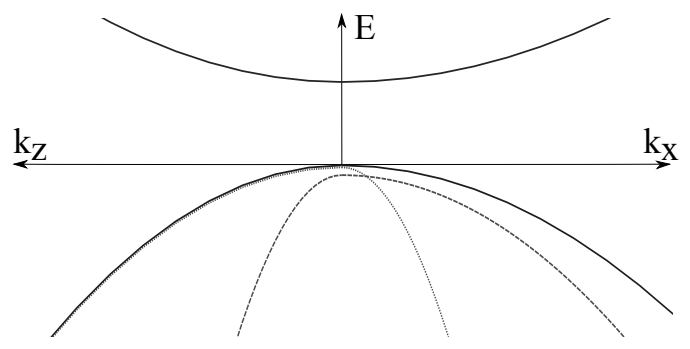

Figure 2.3: Wurtzite InGaN band structure for small $\mathrm{k}$ values in the $\mathrm{x}$ and $\mathrm{z}$ directions.

from the valence band across the band gap $E_{g}$ to the conducting band if $E>E_{g}$ (see figure 2.4). The electron and the hole will relax some of their energy and most of the emitted light from the recombination of the electron and the hole will have an energy close to $E_{g}$.

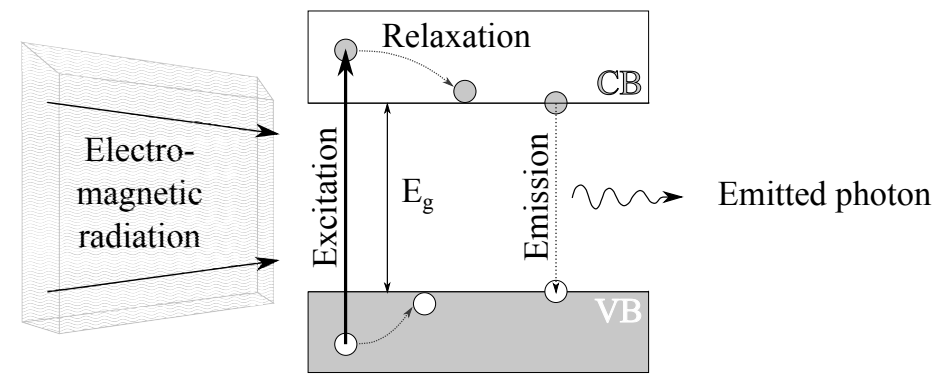

Figure 2.4: Electromagnetic radiation from e.g. a laser with an energy exceeding $E_{g}$ excite electrons to the conducting band (CB) leaving holes in the valence band (VB) the electron and hole relax before they recombine by emitting a photon.

Radiative recombinations could be affected by defects and impurities which typically generate levels in the band gap and then strongly change the emission properties. Even for a perfect semiconducting crystal, there could be emission with an energy slightly less than $E_{g}$. An electron at the bottom of the conduction band, and a hole at the top of the valence band, could if they are spatial close enough to be affected by the attractive Coulomb interaction create an electron hole pair. This electron hole pair affected by Coulomb forces is called an exciton and its emission energy is slightly less 
than $E_{g}$. There is also a possibility for other exciton like interactions involving a few electrons and holes giving emission energies similar to the exciton.

\subsection{Quantum dots}

In a quantum dot, the charges are confined in all three dimensions by a heterostructure as seen in figure 2.5a, in witch a narrower band gap semiconductor is sandwiched between a semiconductor of wider band gap. This is made in all three spatial dimensions leaving the narrow band gap material like an inclusion (figure 2.5b) in the bulk of a wider band gap semiconductor. If the dimension of the inclusion is nanoscopic, quantum mechanical effects will dominate, as characteristic for a quantum dot (QD). The interface between the two semiconductor materials is aimed to be abrupt but the crystal orientation is preserved, putting constraints on the materials used to have similar lattice constants. The nanoscale confinement in a QD brings a transition from continuous to discontinuous density of states, $\rho_{D O S}^{0 D} \propto \delta\left(E-\epsilon_{n}\right)$, where $\delta$ is Kronecker delta and $\epsilon_{n}$ are the energy level energies. A quantum dot will have discrete energy levels (see figure 2.5a) like an atom and is therefore often referred to as an artificial atom. After the recombination of an electron hole pair with photon emission, the energy levels have to be re-populated before a new emission of a photon originating from a recombination from the same energy levels can occur. A QD is therefore an example of a single photon emitter $[17,8]$.

The difference in band gap between the two semiconductor materials will determine the confinement potential. Depending on the semiconductor materials chosen, the confinement, could be of different depth for the valence/conducting band, ending up in one or more allowed energy levels (figure 2.5a). For a type 1 quantum dot, there is a spatial confinement for both electrons and holes. To be able to keep the charges confined in the quantum dot for higher temperatures a deep confinement is needed to prevent the charges to escape from the confinement because of thermal excitation. Any difference in lattice constant between the two semiconductors introduce strain in the quantum dot inclusion affecting the energy levels of the quantum dot. Also the size and shape of the quantum dot will affect the energy levels [18]. 
a)

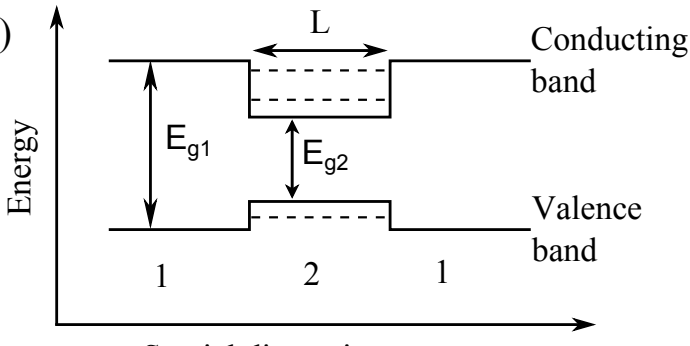

Spatial dimension $\mathrm{x}, \mathrm{y}$ or $\mathrm{z}$ b)

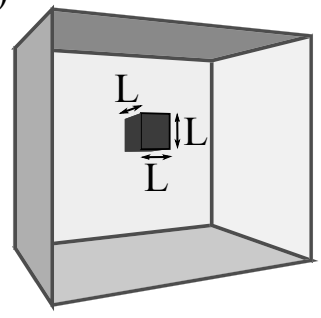

Figure 2.5: a) An illustration of a double heterostructure with the low band semiconductor (2) in the middle. b) Quantum dot formation needs confinement in all three directions with an appropriate size (L).

\subsection{Excitonic complexes}

a)

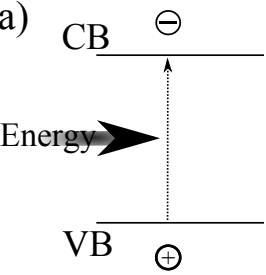

b) $\ominus \longrightarrow$

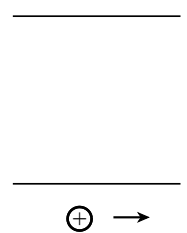

c)
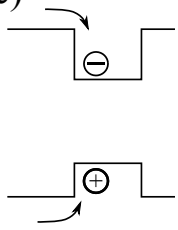

d)

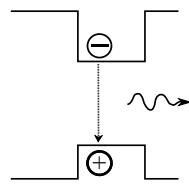

Figure 2.6: How electrons and holes could get trapped in a QD. a) A photon excites an electron hole pair, b) the charges relax to the band edge, c) when the charges encounter a $\mathrm{QD}$, further relaxation traps the charges in the confinement. d) The electron hole pair recombines by sending out a photon.

When a semiconductor with quantum dot inclusions is exposed to light of sufficient energy, electron-hole pairs are created. The charges will spread out and some will encounter the lower potential of a quantum dot and get trapped (see figure 2.6). Besides the exciton $(X)$ as seen in figure 2.7 other excitonic complexes can be formed. If two electrons are trapped with one hole an negative trion is formed $\left(X^{-}\right)$and consequently an electron trapped with two holes is called a positive trion $\left(X^{+}\right)$, and finally two electrons and two holes form a biexciton $(2 X)$. 
a) $\mathrm{x}$

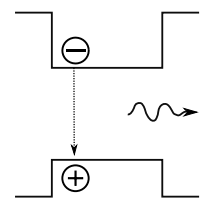

b) $x^{-}$

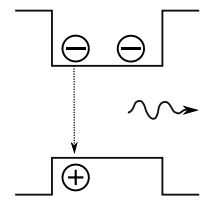

c) $\mathrm{X}^{+}$

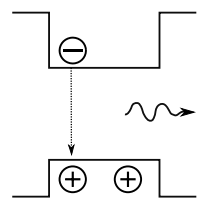

d) $2 \mathrm{X}$

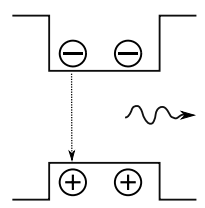

Figure 2.7: Different excitonic complexes a) exciton b) negative trion c) positive trion d) biexciton.

\section{7 $\quad$ Fabrication of quantum dots}

Quantum dots could be grown both with a physical vapor deposition (PVD) technique or with a chemical vapor deposition (CVD) technique. The samples used in this work are grown in a metal organic CVD (MOCVD) reactor.

In a MOCVD reactor for growth of nitrides, metal-organic precursor gases with the wanted atoms (e.g. In and $\mathrm{Ga}$ ) attached deliver, together with an inert carrier gas and $\mathrm{NH}_{3}$, the wanted atoms to the heated substrate. The high temperature causes the organic gases to crack, leaving the building blocks for the wanted film to be grown on the substrate. By changing the partial pressures of the gases and the growth temperature, an epitaxial film with wanted composition of $\operatorname{In}_{x} \mathrm{Ga}_{1-x} \mathrm{~N}$ can in principle be grown.

a)

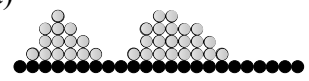

b)

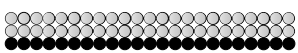

c)

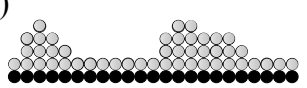

Figure 2.8: Different growth modes of thin films. a) VolmerWeber growth b) Frank-Van der Merwe growth and c) StranskiKrastanov growth.

There are different heteroepitaxial growth modes, i) a thin film could grow forming 3D islands directly (Volmer-Weber) on the substrate or ii) grow layer by layer (Frank-Van der Merwe) or iii) have a mixed growth (StranskiKrastanov) where initially the growth is layer by layer but then switch to island growth as illustrated in figure 2.8. In a lattice matched system, the growth is layer by layer (2D) but for an increasing mismatch of the lattice parameter, the growth mode will change to the mixed growth. For even larger mismatch the growth will be $3 \mathrm{D}$, to be able to reduce the elastic energy. As described earlier an epitaxial structure of two wide band gap semiconductor 
layers with a thin narrow band gap semiconductor layer in the middle forms the double heterostructure where the QDs are formed in the middle layer.

If islands of an appropriate size $(\sim 10 \mathrm{~nm})$ are grown in the middle layer, a dens population of QDs are formed, randomly spread over the sample. The QDs grown in this manner are usually too dense, to be able to resolve emission from a single QD.

In reference [19] the double heterostructure is grown layer by layer and after the growth most of the heterostructure is removed by lithography and etching, just leaving pillars of the layered structure with an appropriate size for QD formation.

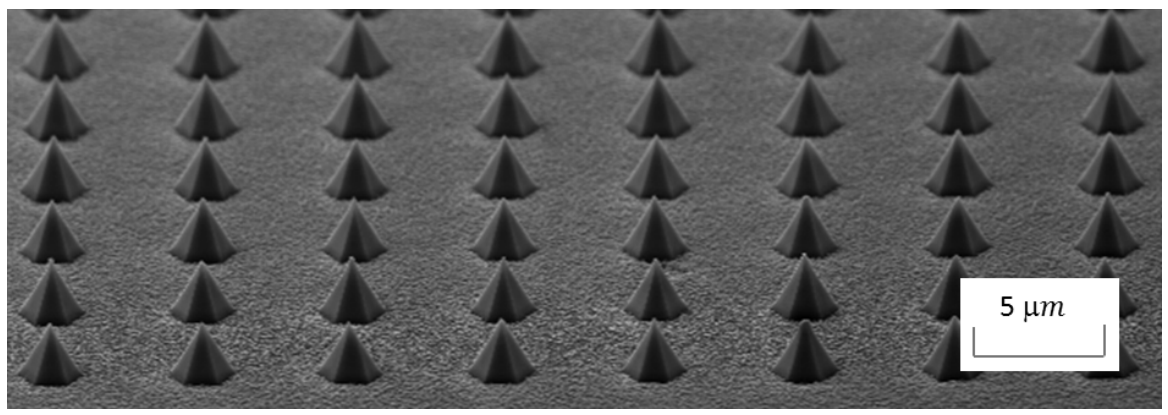

Figure 2.9: A SEM picture of the hexagonal pyramids.

A different approach is to grow 3D islands directly on the substrate (e.g. (111)Si). From these islands nanowires are grown, in which a thin layer of narrow band gap material is incorporated in the nanowire during growth $[20$, 21]. A random dense forest of nanowires, with one QD in each, are the result, but to study the photoluminescence from such a single QD in a nanowire they have to be mechanically removed and dispersed on another surface.

The samples used in this study are of still another type, where hexagonal GaN pyramids are grown by selective area growth (SAG), in lithographically patterned circular openings in the SiN masked GaN covered substrate. The pyramids are not completed but ends with a slight truncated top surface (0001) where a thin film of InGaN followed by a capping layer of GaN is grown. In the InGaN layer forms, under highly optimized conditions, one island inclusion on each top surface, because of the small area available. In this way one QD could be formed on each site-controlled micropyramid (figure 2.9). 


\section{Chapter 3}

\section{Photoluminescence spectroscopy}

\subsection{Photoluminescence spectroscopy}

Photoluminescence (PL) spectroscopy is a widespread technique for optical characterization of semiconducting materials $[22,23]$. The reason for this widespread use is that it is relatively simple to perform and does not require any special sample preparation and it is also non destructive.

In PL measurements, the electron-hole pairs are generated locally in the sample by the energy delivered from a laser beam. The electrons and holes relax their excess kinetic energy, and subsequently the electrons and the holes recombine by emitting photons (figure 2.6) corresponding to the energy difference between the energy levels of the electron and the hole. Emitted photons are guided and focused onto the entrance slit of a monochromator acting as a optical band pass filter, directing the photons with the wanted energy interval to a detector that could be of multichannel or single channel type.

For a charge coupled device (CCD) multichannel detector, the photons are transformed to charges confined to a certain pixel of the CCD, depending on the photon energy. The number of pixels and their size on the CCD gives the energy range and resolution for a given monochromator with a fixed entrance slit. For a single channel detector the photons impinging on the active area are also recorded but there is only one light sensitive area, therefore the monochromator has to be stepped to a slightly different energy 
range between each measurement point. Sometimes, depending on the size of the active area of the detector, an exit slit have to be used to reduce the energy range hitting the active area and thereby improving the energy resolution.

The information gained is transferred into a computer that displays a diagram of the intensity of photons at different energies i.e. a PL-spectrum. The samples are often cooled in a cryostat to give higher intensity and less broad peaks.

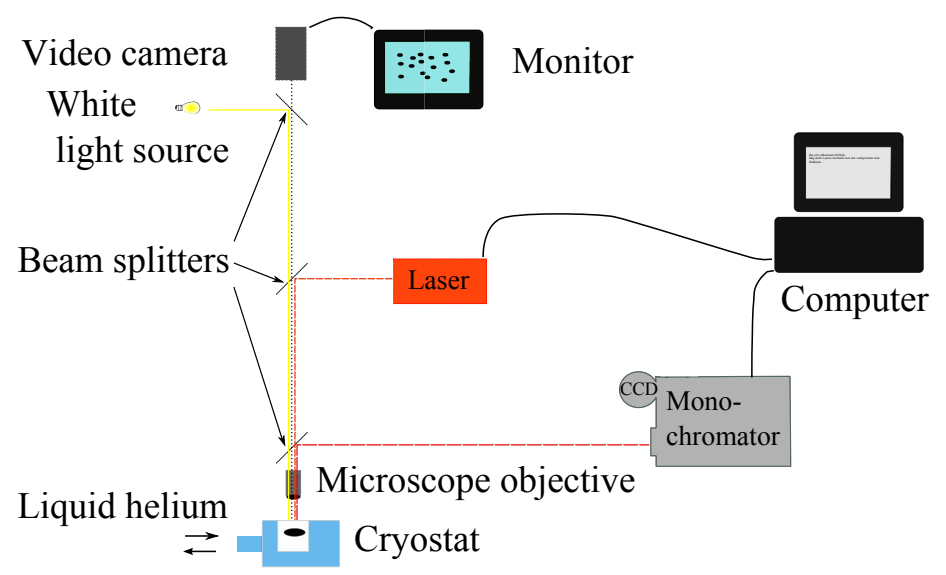

Figure 3.1: A schematic drawing of the main components in a $\mu$ PL setup.

\subsubsection{Micro-photoluminescence spectroscopy}

When PL spectroscopy is to be used to measure on a small area (e.g. single QDs) the laser has to be focused onto as small spot as possible to prevent excitation of other emitters nearby. These well focused beams are necessary for PL spectroscopy on individual QDs. If the laser beam is focused down to micrometer size on the sample surface by a objective, the measurement technique is referred to as $\mu \mathrm{PL}$ spectroscopy. The fact that the QDs are site controlled (5 $\mu \mathrm{m}$ pitch) makes it possible to measure on an individual QD. Otherwise mesas can be used to isolate the emission from an individual QD. A live image of the sample is provided by a white light source projecting an image of the sample onto a video camera. Manipulators, in the $\mathrm{x}, \mathrm{y}$ and $\mathrm{z}$ - 
directions, are used to position and focus the sample. The main components of a $\mu \mathrm{PL}$ setup is seen in figure 3.1.

The diffraction limited resolution is given by $d=\lambda /(2 \cdot \mathrm{NA})$ where $\lambda$ is the laser wavelength and NA is the numerical aperture of the objective [24]. This gives $d=0.4 \mu \mathrm{m}$ for the most used objective (see 3.2.2). This theoretical limit is not reached because of the uncorrected aberration from the thickness of the cryostat window. The spot size is estimated to be $\sim 1 \mu \mathrm{m}$, this is very large compared to the size of the QD size of a few tens of a $\mathrm{nm}$.

The laser is not only illuminating the QD but also a finite volume around it. In this volume are the QD but also other emitters fed with electron hole pairs, creating a background emission in addition to the QD emission. In figure 3.2 a $\mu \mathrm{PL}$ spectra of a $\mathrm{QD}$ emission with one dominating peak is seen on a flat background originating from the ambient volume. The parameter $\rho$ is defined as the intensity of the wanted QD emission (S) divided by the total signal $(\mathrm{S}+\mathrm{B})$, i.e. $\rho=(\mathrm{S} / \mathrm{S}+\mathrm{B})$, for a chosen wavelength. The parameter $\rho$ is important for correlation measurements and will be discussed more in Chapter 5.

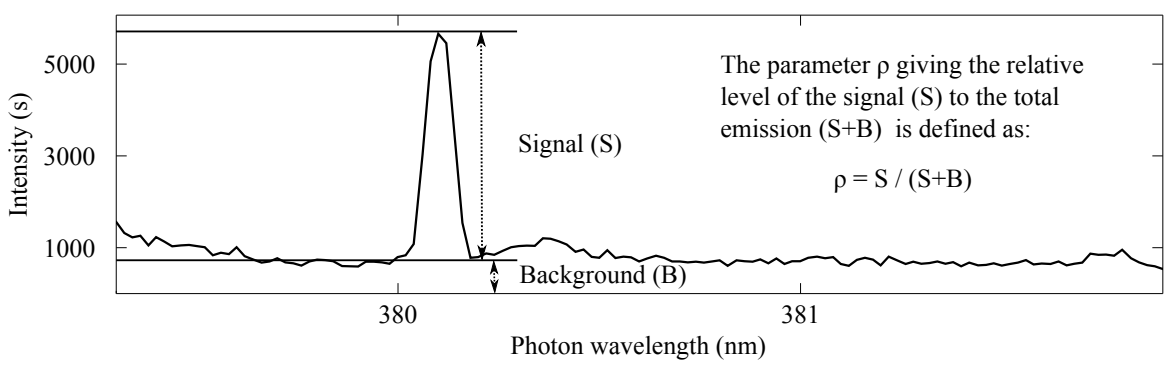

Figure 3.2: A $\mu \mathrm{PL}$ spectra of a $\mathrm{QD}$ emission with one peak, is used as an example on how the $\rho$ values is determined. $S$ is the intensity of the QD emission wanted to reach the detector, $B$ is the intensity of the unwanted background emission also reaching the detector. From $S$ and $B, \rho$ is calculated with the expression seen in the figure.

The settings of the exit slit for a given monochromator with a well focused light beam $(\sim 20 \mu \mathrm{m})$ on the entrance slit defines the wavelength interval transmitted to the detector. If this wavelength interval is larger than the spectral width of the emission peak, the background on each side will also contribute to the amount of photons counted by a single channel detector 
(see figure 3.2). More photons from the background will reach the detector and thus a smaller $\rho$ value will be the result.

\subsubsection{Time resolved $\mu$ PL-spectroscopy}

Different emissions have in general different time constants and there are two common ways to measure the time from excitation to emission. The first involves a single photon detector and the other uses a streak camera as detector of the filtered light from a monochromator. Both methods require a pulsed laser as excitation source. As there were single photon detectors in the correlation setup these were used for the time resolved $\mu \mathrm{PL}$-spectroscopy $(\mathrm{TR} \mu \mathrm{PL})$ measurements. The pulses from a laser are used both to excite the sample and to start a timing device. Subsequently a photon from the desired emission stops the time measurement. This time is incrementing the appropriate bin in a histogram by one and the measurement are repeated multiple times $\left(\sim 10^{5}\right)$ to get a histogram from which the time constants can be determined.

The streak camera on the other hand works by transforming the temporal profile of the emission to a spatial profile on the detector. In the streak camera the photons hit a photo-cathode in a cathode ray tube and produces electrons which are accelerated and led through a time-varying electric field, perpendicular to the velocity of the electrons. The time-varying electric field (which is synchronized with the laser pulses) deflects the electrons and sweeps them over a phosphorus screen at the end of the vacuum tube. A CCD is used to measure the streak pattern on the screen, and from this pattern the time constant can be extracted.

\subsubsection{Polarized $\mu \mathrm{PL}$-spectroscopy}

Some emissions are linearly polarized and the level of linear polarization can be measured. Measurements are performed by introducing a half wave plate into the beam path of the emission, turned until the maximum intensity is registered on the CCD. This is done to have the polarization direction of the emission to coincide with the direction where the grating inside the monochromator has highest reflectance. A polarizer is then introduced between the half wave plate and the monochromator and turned to maximum intensity of the emission. A series of $\mu \mathrm{PL}$ spectra for different angles of the half wave plate are taken where a turned angle $\varphi$ on the half wave plate is 
equivalent to $2 \varphi$ rotation of the polarization plane. The data from the integrated intensity of a peak is conveniently plotted against the polarization angle $2 \varphi$ in a polar plot.

\subsection{Apparatus}

\subsubsection{Excitation sources}

In this work, the most frequently used laser was a $355 \mathrm{~nm}$ continuous wave diode pumped solid state laser. A frequency tripled Ti-sapphire laser generating ps pulses at $266 \mathrm{~nm}$, was also used.

\subsubsection{Objectives}

Mainly three microscope objectives were used. For measurements on InGaN QDs, a refractive objective, Mitutoyo MPlan Apo NUV 50×, with a numerical aperture of $\mathrm{NA}=0.42$ giving a diffraction limited resolution of $d=0.4$ $\mu \mathrm{m}$ for $\lambda=355 \mathrm{~nm}$ was used. Also a reflecting objective, Ealing 25-0548-000 $36 \times$, with $\mathrm{NA}=0.5$ giving $d=0.3 \mu \mathrm{m}$ was used for measurements with $266 \mathrm{~nm}$ laser wavelength. For the initial measurements on InGaAs QDs a microscope objective with $\mathrm{NA}=0.55$ was used giving $d=1.4 \mu \mathrm{m}$ for $\lambda=$ $750 \mathrm{~nm}$.

\subsubsection{Cryostat}

A liquid Helium flow cryostat was used to cool the sample. By means of a unit controlling the Helium flow, and the current through a heater inside the cryostat, a stable temperature from room temperature down to $4 \mathrm{~K}$ was maintained during a measurement. The sample is optically accessed through a window in the cryostat that transmits the laser and PL signal. The sample is in turn mounted on a could finger connected to the liquid Helium.

\subsubsection{Detectors}

The used CCD-detector was cooled by liquid Nitrogen to lower the noise level. The CCD comprises of $256 \times 1024$ square pixels each of $26 \mu \mathrm{m}$ size. Mostly a diffraction grating with 1200 groves per mm was used giving an 
energy resolution between two pixels of $0.28 \mathrm{meV}$ for the relevant energy range. The 1024 pixels gives an energy range of $\sim 300 \mathrm{meV}$ corresponding to a wavelength interval of $\sim 40 \mathrm{~nm}$ for the wavelengths used. For every of these pixels there are a 256 pixels high column perpendicular to the scan direction which often are binned, to give one value of the photon intensity for the given wavelength. The photons absorbed in a certain pixel are transformed to charges that are read out to the computer.

Two different types of single channel detectors where used, a singlephoton avalanche diode (SPAD) with $2.3 \mathrm{meV}$ energy resolution and a photomultiplier tube (PMT) with $0.86 \mathrm{meV}$ energy resolution for the chosen slit settings of the monochromator. These detectors where also used for the correlation measurements and more data are given in section 4.4.1.

\subsubsection{Filters}

Besides the beam splitters necessary for the proper function of the setup, some filters have been used. With the help of a neutral density filter the intensity of the laser beam could easily be changed by several magnitudes, accordingly changing the flux of photons into the material.

A ultra sharp edge long pass filter that prevents the high intensity laser wavelength from entering the monochromator, but allows longer wavelengths to pass, makes it easier to measure close to the laser wavelength and it also lowers the background emission by reducing the stray light in the monochromator. A linearly polarized filter could also be used to lower the background emission by blocking the background emission that is not polarized in the same direction as the measured QD emission. 


\section{Chapter 4}

\section{Time correlated single photon spectroscopy}

\subsection{Introduction}

The time correlated single photon spectroscopy (TCSPS) measurement method was developed by astronomers Hanbury-Brown and Twiss (HBT) in the mid 1950s to measure the diameter of stars. They developed a new type of correlation experiment that is based on the correlation of intensities instead of electric field amplitude. An article was published where they tested their method on an mercury lamp [25] and later the same year they published measurements on the diameter of the star Sirius [26] but also a defense [27] of their new found method. Filtered monochromatic light from a small aperture in a mercury lamp originates from the emission of many millions of atoms and fluctuations in intensity will occur on time scales comparable to the coherence time $\tau_{c}$. The intensity variation arises from the sum of randomly phased light sources. If we measure the intensity $I(t)$ at $t$ and $t+\tau$ for $\tau>\tau_{c}$ the two intensities will not be correlated but for times shorter than $\tau_{c}$ there will be a positive correlation.

In their measurements on star diameters they measured spatial coherence and by increasing the distance between the detectors until there was no correlation they could calculate the apparent angle of the star [28, 29, 30, 31], by knowing the distance to the star the diameter could be calculated.

Rebka and Pound was the first to measure the time correlation instead of the spatial correlation as HBT did [32]. In our case we measure the 
correlation from a fixed point, as the light is emitted from a QD, so let us turn our focus to the temporal coherence of a light source.

\subsubsection{Theoretical basis}

We introduce the second order coherence function defined by,

$$
g^{(2)}(\tau)=\frac{\langle I(t) I(t+\tau)\rangle}{\langle I(t)\rangle\langle I(t+\tau)\rangle},
$$

where $\langle I(t)\rangle$ is the time average of the intensity of the light beam at time $t$. The parenthesis around 2 in $g^{(2)}(\tau)$ is used to stress the fact that the superscript 2 is not an exponent but second order. For comparison, the first order coherence function, $g^{(1)}(\tau)$ is a similar expression with the electric field vector instead of intensity in the expression of 4.1. An example of when a first order coherence function appear is in a Michelson interferometer experiment where the visibility of the fringes are related to $g^{(1)}(\tau), \tau$ is here the time difference between the two paths traveled by the light in the interferometer.

If we have a perfectly coherent monochromatic light source with time independent intensity then $\langle I(t)\rangle=\langle I(t+\tau)\rangle=I$ and 4.1 could be written,

$$
g^{(2)}(\tau)=\frac{\langle I(t) I(t+\tau)\rangle}{\langle I(t)\rangle\langle I(t+\tau)\rangle}=\frac{I^{2}}{I^{2}}=1 .
$$

A coherent light source have Poissonian photon statistics and the time between individual photons is completely random, but for all other classical light sources, like black body radiation and discharge tubes, the light is called partially coherent or chaotic. Consider a chaotic light source with a constant average intensity. When $\tau \gg \tau_{c}$ the second order coherence function $g^{(2)}(\tau)_{\tau \gg \tau_{c}}=1$ because there is no correlation between $I(t)$ and $I(t+\tau)$ so $\langle I(t) I(t+\tau)\rangle=\langle I(t)\rangle\langle I(t+\tau)\rangle$. But for small $\tau, I(t)$ and $I(t+\tau)$ are correlated $\langle I(t) I(t+\tau)\rangle>\langle I(t)\rangle\langle I(t+\tau)\rangle$ and therefore $g^{(2)}(\tau)_{\tau \ll \tau_{c}}>1$ for $\tau \ll \tau_{c}$. In particular for $\tau=0$,

$$
g^{(2)}(0)=\frac{\left\langle I(t)^{2}\right\rangle}{\langle I(t)\rangle^{2}}>1
$$

Generally, all classical light sources have $g^{(2)}(0) \geq 1$ and $g^{(2)}(0) \geq g^{(2)}(\tau)$ where $g^{(2)}(0)=g^{(2)}(\tau)=1$ is valid for coherent light. 
A non classical light source have $g^{(2)}(0)<1$, which is the requirement for anti-bunching, but also $g^{(2)}(0) \leq g^{(2)}(\tau)[33,34$, page 171]. Consider a single atom, with two energy levels where the emission of a photon corresponding to the energy differences between the two levels have to be followed by an absorption of energy before a new emission can take place. There can not be two photons emitted simultaneously so for an ideal case $g^{(2)}(0)=0$, and also short time intervals will be underrepresented, but still $g^{(2)}(\tau)=1$ for large values of $\tau$. The first antibunching measurement was performed on Sodium atoms in 1977 [35] and the first antibunching with a QD as a single photon emitter was published in year $2000[11,36]$. The time differences between the photons for the different cases discussed above, and the corresponding $g^{(2)}(\tau)$ diagrams, are summarized in figure 4.1.

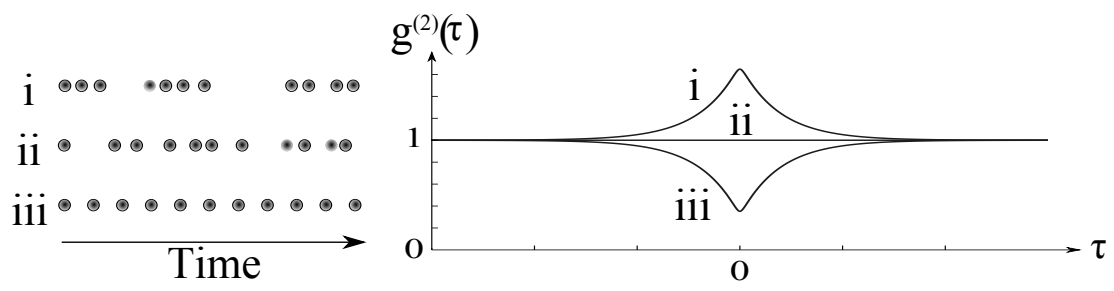

Figure 4.1: Left: Streams of i) bunched ii) coherent (random) and iii) anti-bunched photons. Right: The principal behavior of the Second order coherence function $g^{(2)}(\tau)$ for i) bunched ii) coherent and iii) anti-bunched light.

The use of the method invented by HBT have up to now found limited use in astronomy $[37,30]$ but has played a major role in quantum optics measurements. The quantum optics relevant for this work has been further elucidated by Fox [38], which book has been followed here, and by Glauber [39], which has a more mathematical treatment. Glauber received the Nobel prize in Physics, 2005 'for his contribution to the quantum theory of optical coherence' [40].

\subsubsection{TCSPS measurements}

A schematic TCSPS apparatus as shown in figure 4.2 is similar to a $\mu P L$ apparatus (figure 3.1) but the signal side is altered. The stream of photons emitted from the sample is split into two by a $50 / 50$ beam splitter, directing 


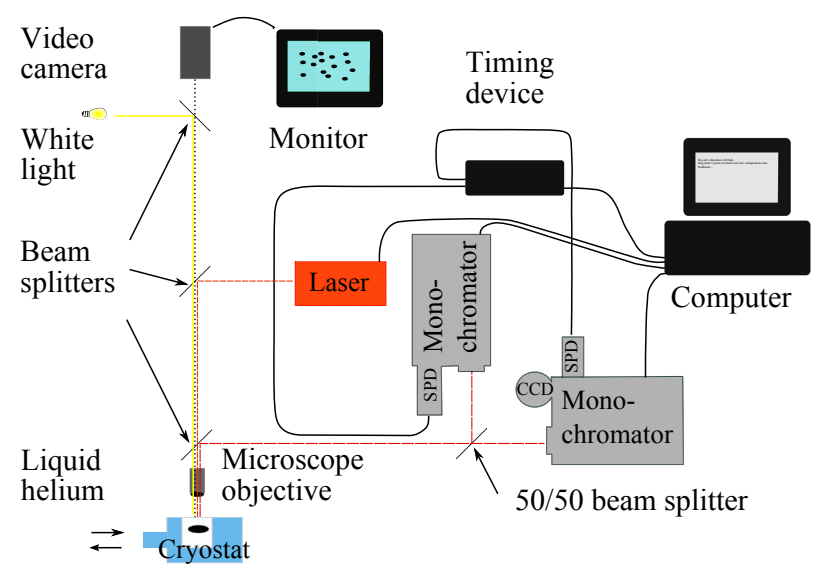

Figure 4.2: A schematic drawing of the main components of a TCSPS setup. Compared to a $\mu$ PL setup, the signal side is altered with a 50/50 beam splitter directing the signal to two monochromators giving almost monochromatic photons to the single photon detectors (SPD). The electrical impulse present on the output of the SPD after the detection of a photon is led to a control unit where the time differences are determined and a histogram is constructed in the computer.

the beams through the monochromators selecting the wanted wavelengths hitting the single photon detectors (SPD). The SPDs have a finite probability to detect a single photon. The single photon detectors (here called SPD1 and SPD2) can be regarded as timing devices where SPD1 starts a clock when a photon is detected and SPD2 stops the clock when it detects another photon. As the beam splitter can not divide photons, one photon can not both start and stop the clock, the photons have to choose direction towards SPD1 or SPD2. The time differences between SPD1 and SPD2 is sent to a timing device, and the counts for each time interval is usually displayed in a histogram. The time intervals, i.e. the bin width of the histogram could be chosen in the range of $4 \mathrm{ps}$ to $512 \mathrm{ps}$ for the timing device in the setup (Picoharp 300). As the number of counts is proportional to the flux of photons per second, i.e. the intensity, the correlation histogram, normalized to unity is a measurement of $g^{(2)}(\tau)$, 


$$
g^{(2)}(\tau)=\frac{\left\langle n_{1}(t) n_{2}(t+\tau)\right\rangle}{\left\langle n_{1}(t)\right\rangle\left\langle n_{2}(t+\tau)\right\rangle},
$$

where $n_{1}(t)\left(n_{2}(t)\right)$ are the detected photons from SPD1 (SPD2). Note that $g^{(2)}(\tau)$ is given by the normalized measured histogram only when the detection probability is low [41]. This is normally of no concern as just a few percents of the emitted photons entering the collective objective are detected by the SPD, as the emitted photons have to pass through the collecting objective, some optics and beam splitters (see figure 3.1) before reaching the SPD with its limited detection probability.

It should also be pointed out that the measurement of $g^{(2)}(\tau)$ however, is affected by limited statistics and experimental imperfections to be discussed later.

In TCSPS measurements the integration time is proportional to the photon intensity squared. A factor of ten increase of the photons detected result in a decrease of the time required to get a histogram with a factor of 100 . Therefore, detectors with high detection probability and optical components optimized to the actual wavelengths together with samples of good quality are crucial to get a high quality result, in a time frame reasonable for practical experiment.

\subsubsection{Quantum dots as emitters of correlated photons}

If photons impinging on both of the SPDs originate from the same spectral line of the QD no events at $\tau=0$ should be seen. There should be no photons of the same energy leaving the QD simultaneously and $g^{(2)}(0)=0$. Usually there is some background emission overlapping with the QD emission and also the TCSPS instrument has a finite time resolution that introduce statistical uncertainties in the measured times. The uncorrelated emission as well as the instrument time resolution tends to destroy the quality of the correlation spectra, forcing $g^{(2)}(\tau)$ towards 1 for small $\tau$. In the case of antibunching, $g^{(2)}(0)$ will be larger.

A correlation experiment where the two detectors measure light from the same emission line is called an autocorrelation measurement. Similarly if the two detectors are set to different emission lines, the resulting histogram is referred to as a cross-correlation.

Now follows a discussion of the differences in the appearance of the different correlation histograms for a continuous and for a pulsed laser excitation 
source. All the exemplifying histograms shown in this chapter are from measurements of InGaAs pyramidal QDs, grown by E. Pelucchi and co-workers at Tyndall national institute, Corc, Ireland [42].

\subsection{Continuous laser mode}

The slope of the dip in an autocorrelation histogram is given by $\tau_{c}$, the characteristic anti-bunching time, this is in general different from the emission life time, e.g. $\tau_{x}$, because of effects from the non-ideality of the TCSPS apparatus and the bin width used as discussed in chapter 5 , but also from the feeding of charges to the QD. For low laser power the QD charge feeding is low and the effect on the characteristic anti-bunching time is small [36].

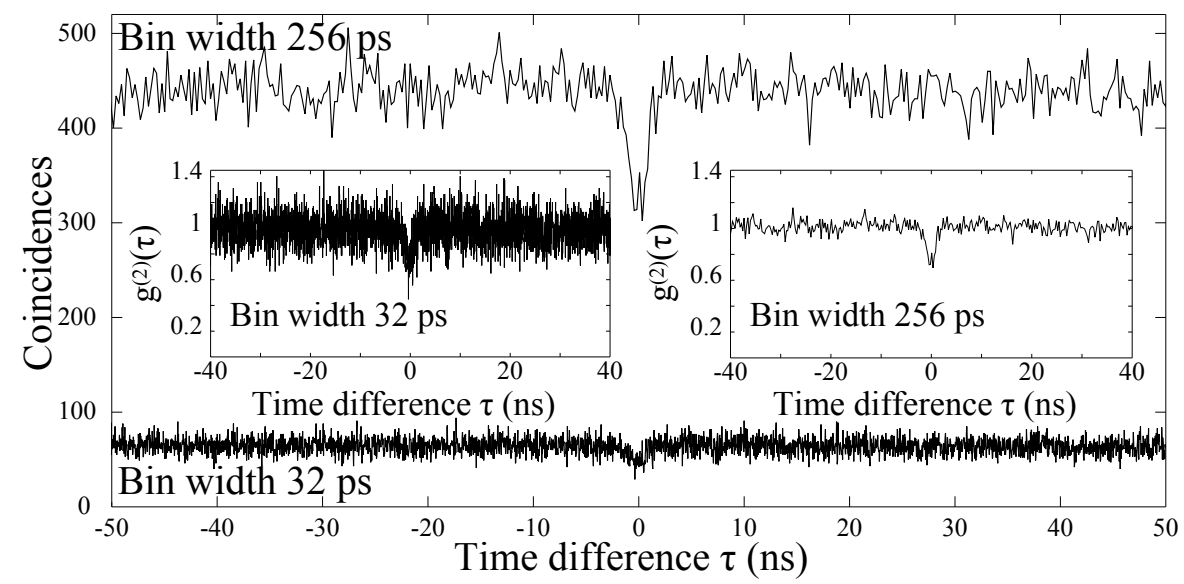

Figure 4.3: Comparison of the appearance of the correlation histograms, at equal measurement time, for two bin widths $32 \mathrm{ps}$ and $256 \mathrm{ps}$. The inserts show the normalized histograms of the same measurements.

By choosing a smaller bin width there will be less counts in each bin for a given time and a statistical fluctuation of a few counts in a bin will have a larger influence for a lower number of counts in the bin. In figure 4.3 this is shown for bin width, 32 ps and 256 ps respectively. The coincidence counts for $256 \mathrm{ps}$ bin width is about 8 times larger than the counts for the 32 bin width data, as expected from the bin width ratios. The normalized $g^{(2)}(\tau)$ 
histogram from the coincident data is significantly more noisy for the lower bin width as can be seen in the two inserts of figure 4.3. A shorter bin width will give more detailed information on the behavior around $g^{(2)}(0)$ but e.g. using half the value of the bin width will cause a doubled measurement time to obtain the same average number of counts in each bin.

With a continuous laser, the emitted photons come in a steady stream, and examples of histograms obtained are shown in figures 4.4 to 4.6. Figure 4.4 shows examples of autocorrelation histograms and it is seen that $g^{(2)}(\tau)<1$ for small $\tau$ and the $g^{(2)}(0)$ value is low, showing anti-bunching of detected photons with small $\tau$. A further analysis of the used parameters and the background emission level of the $\mu \mathrm{PL}$ spectra has to be done to determine the quality of the single photon emitter. The bunching at intermediate $\tau$ in figure $4.4 \mathrm{~b}$, is due to that the feeding of electrons and hole pairs is faster than the QD switches charge state, it is therefore an increased probability that two subsequent photons originate from excitons with the same charge state.
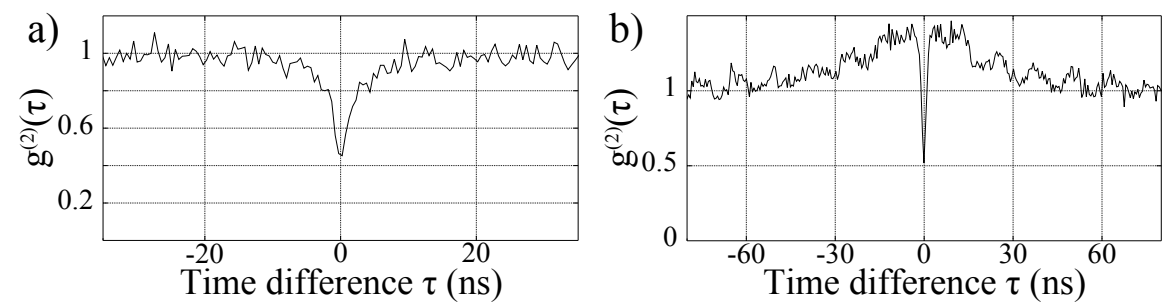

Figure 4.4: Measured autocorrelation histograms of a) the emission from $X^{+}$and b) the emission from $X^{-}$.

In an anti-bunching cross-correlation histogram there are in general different characteristic times for the start and stop emissions. An example of this is seen in figure 4.5a, where a photon from biexcitonic emission, $2 X$, start the clock and photons from $X^{+}$emission stop the clock. The histogram is asymmetric and the reason for this is, besides the difference in life times that after a $2 X$ emission the QD is left with an electron hole pair and just one extra hole is needed for a subsequent $X^{+}$emission. On the contrary, if a $X^{+}$emission occur, the QD is left with just a hole and it will in general take longer time to fill the QD with the two electrons and one hole needed for a subsequent $2 X$ emission. In figure $4.5 \mathrm{~b}$, a very wide cross-correlation histogram is shown between $X^{+}$(start) and $X^{-}$(stop). The $X^{+}$emission 

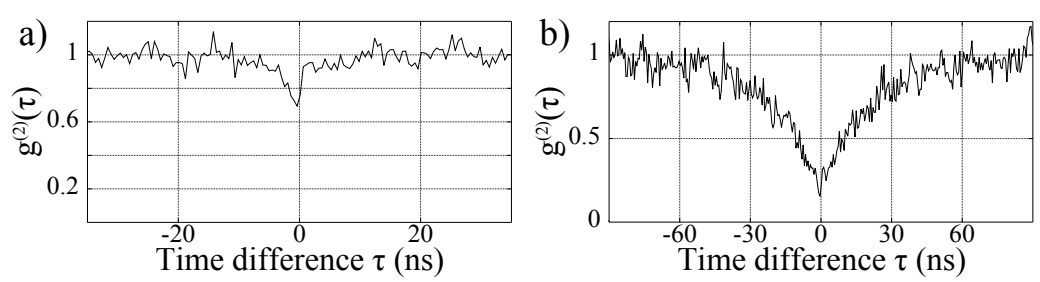

Figure 4.5: Measured cross-correlation histograms of a) the emission from $2 X$ (start) and $X^{+}$(stop) and b) the emission from $X^{+}$(start) and $X^{-}$(stop).

leaves a hole in the QD and two electrons are needed to obtain the configuration required for a $X^{-}$emission. Since the exciting laser produces the same amount of electrons and holes there is a strongly reduced probability that two subsequent photons originate from excitons with opposite charge states, resulting in very long times between start and stop events.

The cascade emissions of $2 X$ and $X$ are seen in figure 4.6.

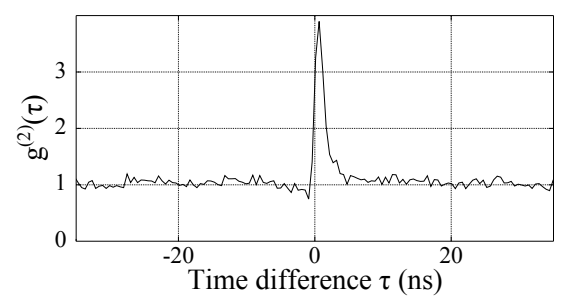

Figure 4.6: Measured cross-correlation histograms of the emission from $2 X$ (start) and $X$ (stop).

\subsection{Pulsed laser mode}

In pulsed laser mode, the laser gives short intense pulses (often ps to fs duration time) of photons with a high repetition frequency $(\sim 80 \mathrm{MHz})$. The large amount of electron hole pairs created, quickly fill the QD and subsequently the excitonic complexes will recombine, emitting photons according to their time constants. Ideally, the laser pulses are shorter than the emission lifetimes involved, and the time between the laser pulses much longer than the emission lifetimes. Normally, the QD is then emptied by recombination 
between each pulse. The special case where the emission lifetime is comparable to the laser repetition time, is described in reference [43]. There is a possibility that the QD is re-populated from charges loosely bound to shallow potential fluctuations in the vicinity of the QD in the time between the pulses. How efficient the re-population is depends on the potential landscape near the QD. By using a longer laser excitation wavelength a reduction of the re-population, if present, might occur.

The correlation histogram will change appearance, compared to continuous laser mode, when the photons will arrive at the SPD predominantly at certain times shortly after each laser pulse. The time difference between the photons that start and stop the timing unit will approximately be in units $(0, \pm 1, \pm 2 \ldots)$ of the repetition time of the laser. For an autocorrelation measurement the contribution at $\tau \approx 0$ must come from the background emission or from re-population between pulses as described above. Since the QD is a single photon emitter the second (stop) photon is either from another source emitting at the same energy or from a emission after re-population [44]. The size of the residual pulse at $\tau \approx 0$ is unaffected by the non-ideality of the TCSPS instrument, as a small statistical spread of the measured time (much smaller than the laser repetition time) just alter the pulse form. The $g^{(2)}(0)$ value is calculated as the sum of the histogram bins for the pulse at $\tau \approx$ 0 divided by an average of the sum of histogram bins for pulses $|\tau| \gg 0$. Correlation histograms with the pulsed laser mode are seen in figures 4.7 and 4.8
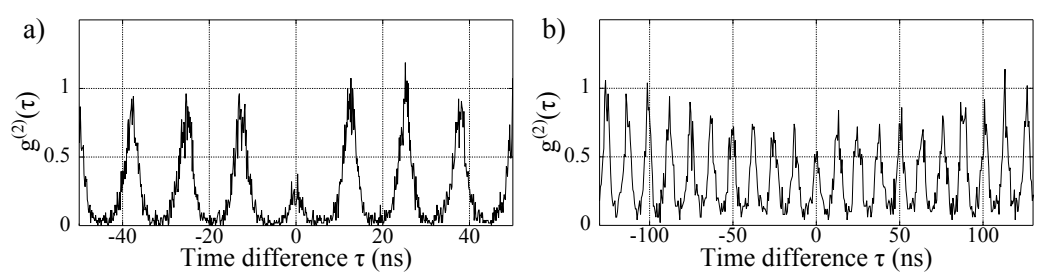

Figure 4.7: Measured histograms of a) an autocorrelation of the emission from $X^{-}$and b) a cross-correlation between the emission from $X^{+}$(start) and $X^{-}$(stop).

The autocorrelation histogram for $X^{-}$in pulsed laser mode is seen in figure 4.7a, where the $g^{(2)}(\tau)$ value is suppressed for $\tau$ values corresponding to the laser pulses at zero time difference. There are in general not two $X^{-}$ photons emitted during the same laser excitation pulse because after the $X^{-}$ 
emission the QD is left with an electron and will normally not be filled until the next laser pulse. The remnant contribution to the correlation histogram at $\tau \approx 0$, visible in the figure is mainly due to uncorrelated background emission. The cross correlation histogram of the cascade event of the emission from $2 X$ (start) and $X$ (stop) is seen in figure 4.8a, where the increased probability of emission of an exciton after the biexciton emission is clearly seen, as a bunching for the central peak on the positive side. An event where there is a re-population of the QD, is seen in figure $4.8 \mathrm{~b}$. Here the capture of an electron, from shallow potential fluctuations in the vicinity of the QD, gives a non-zero probability of exciton emission after the emission of $X^{+}$. Finally a cross-correlation histogram of the emission from $X^{+}$(start) and $X^{-}$(stop) (figure 4.7b), similar to the histogram with continuous laser (figure $4.5 \mathrm{~b}$ ) is shown with its long time between the start and stop events.
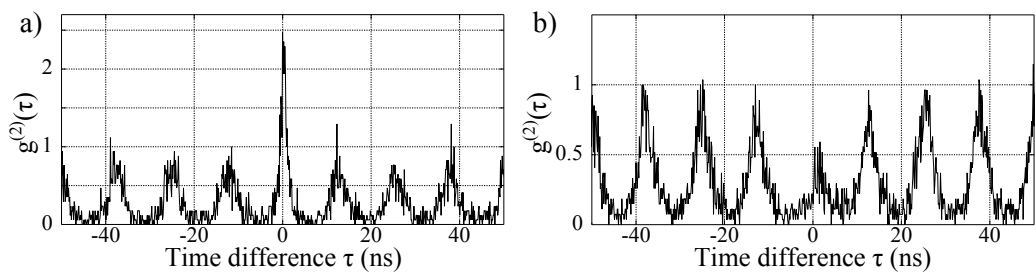

Figure 4.8: Measured cross-correlation histogram of a) the emission from $2 X$ (start) and $X$ (stop) and b) the emission from $X^{+}$ (start) and $X$ (stop).

\subsection{Apparatus}

\subsubsection{Detectors}

Two kinds of SPDs where used, a single-photon avalanche diode (SPAD) and a photomultiplier tube (PMT) [8].

A SPAD is a reverse biased diode at a voltage higher than the break down voltage in which a photo generated carrier can start an avalanche current. A control (quenching) circuit lowers the voltage and generates an output pulse used for time measurements. When the avalanche has stopped it restores the voltage to operation level. The time from a photon is present at the active 
area of the detector till the voltage is back to operational level and the detector is operational again is called the dead time. The time resolution depends on the spot size of the illumination. The specific SPAD used $\tau$ SPAD-100 from PicoQuant has an active area with a diameter of $150 \mu \mathrm{m}$ and a timing resolving power of $>0.35 \mathrm{~ns}$. The dead time, was less than $70 \mathrm{~ns}$.

In a PMT, photo generated electrons are accelerated by an electric field over several electrodes (dynodes) where on each electrode, the electrons are multiplied by secondary emission. After the last dynode a sharp current pulse hits the anode signaling that a photon has hit the photo cathode. The time resolution depends on the alignment of the dynodes, all electrons, both the primary and the secondary electrons, should ideally arrive simultaneously. For the PMT used, PMA 175, also from PicoQuant, the detector area has a diameter of $8 \mathrm{~mm}$ and the timing resolving power is $<0.18 \mathrm{~ns}$ and does not depend on the spot size. The dark counts are comparable for the two detector types and are less than $\sim 50$ counts/s. The spectral response and detection efficiency for the two detectors types are seen in figure 4.9.

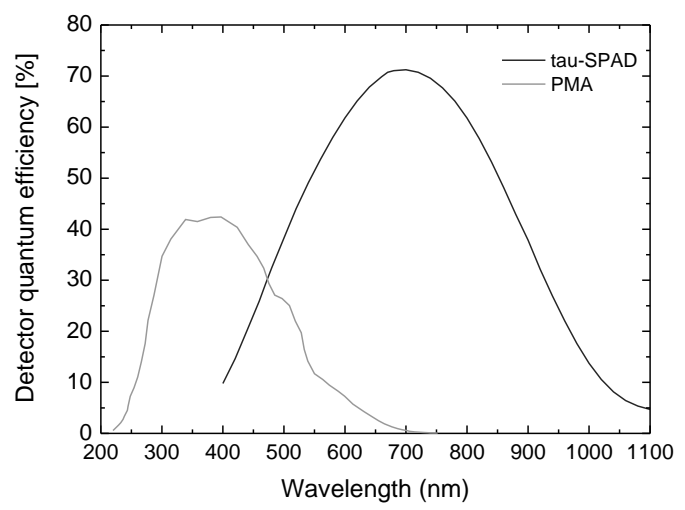

Figure 4.9: Comparison of the detection probability versus wavelength for detectors ( $\tau$-SPAD-100 and PMA 175) used as SPD in the TCSPS setup. Data adapted with permission from PicoQuant [45].

\subsubsection{Instrument time response}

To measure the instrument time response of the TCSPS setup, the light from a pulsed laser is used. The only difference from a standard measure- 
ment is that a mirror is placed before the cryostat reflecting the laser light back through the objective towards the SPDs where one starts and the other stops the timing device. While the laser pulses are of ps duration, the spread of recorded time differences could be regarded to originate almost entirely on the time spread of the components building up the setup, where the major contribution comes from the SPDs. The slope of the peaks in the histogram are of the form $I(t)=I_{0} \cdot e^{-|t| / \tau_{i}}$ and a histogram of the measurements to determine $\tau_{i}$ for the PMT detectors are shown in figure 4.10. A fit together with the histogram data is seen in the insert of figure 4.10 giving the instrumental time constant for the PMTs $\tau_{i}^{P M T}=0.12 \mathrm{~ns}$.

In a similar way the time constant for the SPAD detectors where determined to be $\tau_{i}^{S P A D}=0.7 \mathrm{~ns}$. There are no other changes in the setup besides the detectors so the difference in resolution is solemnly related to the detectors.

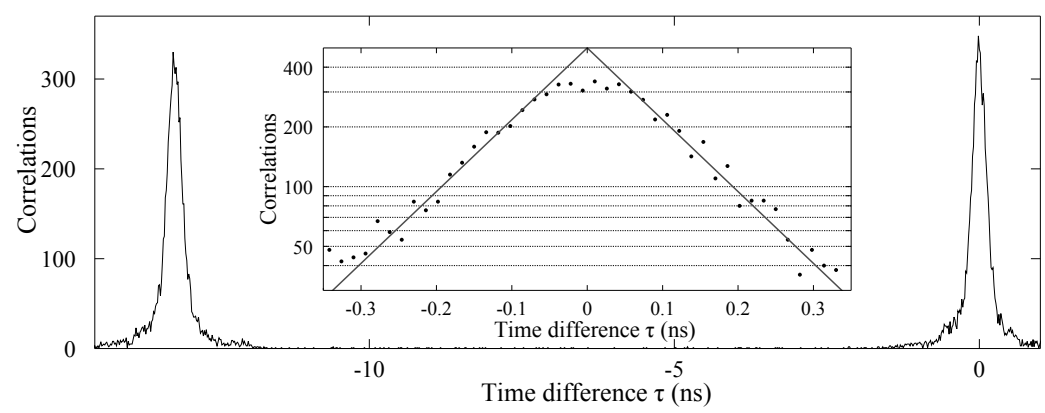

Figure 4.10: The histogram where $\tau_{i}$ for the setup with PMTs were determined. A pulsed laser will trigger both start and stop of the timing device. The insert shows a close up of one peak where the histogram points (bin width $16 \mathrm{~ns}$ ) have been fitted to an exponential curve, $I(t)=I_{0} \cdot e^{-|t| / \tau_{i}}$ where $I_{0}=500$ and $\tau_{i}=$ $0.12 \mathrm{~ns}$, shown as a solid line. 


\section{Chapter 5}

\section{Simulation of TCSPS histograms: effects of experimental non-ideality}

\subsection{Method}

Simulations where made in order to investigate factors that deteriorate the autocorrelation, from the excitonic emission from a QD, in TCSPS measurements. The parameters investigated are the influence from uncorrelated background emission, the dependence on the instrument time resolution and the influence from the bin width of the correlation histogram.

For a Poisson distribution the following three statements are true [46]: i) The probability for an event in a short time interval $(\Delta t)$ is $\Delta t / \tau$ and ii) the probability of having two events in $\Delta t$ is negligible small, and if also iii) the events are independent. Then the probability of having no event in the time $t$ follow a Poisson distribution $P_{0}(t)=e^{-\frac{t}{\tau}}$. As the probability of having two events is negligible small the sum of the probability of having zero or one event in time $t$ equals one $P_{0}(t)+P_{1}(t)=1$. The Poisson distribution give the exponential expression used for lifetime calculations (e.g. $\tau_{x}$ ) which could also be implemented on the instrument time resolution, $\tau_{i}$. The probability for an event $\Delta t / \tau$ in the time interval $\Delta t$ is tested against a random number in a loop, this forms the basis for the simulation. 
In the simulations a random number $A$ between $[0,1]$ is created and if $A \leq \Delta t / \tau$ the event happens. This is applied to the filling of the QD with an electron hole pair ( $\tau_{e h}=10 \mathrm{~ns}$ in all simulations) and to the emission of a biexciton $\left(\tau_{2 X}\right)$ or an exciton $\left(\tau_{X}\right)$. It all takes place in a loop where the simulated measurement time is added by $\Delta t$ in each turn. Depending on if the QD contains, 0, 1 or 2 electron hole pairs, one of the following set could happen. The QD can, (0 electron hole pair) receive an electron hole pair, (1 electron hole pair) emit an exciton related photon or receive an electron hole pair or (2 electron hole pairs) emit an biexciton related photon. A small random number of a statistical time spread $\tau_{i}$ is added to the time of each emission event, corresponding to the instrumental time resolution.

For the background emission an extra comparison with a random number is added in the loop and the random times of background emissions is added to the list of exciton or biexciton emission events. Each simulations gave in average almost 100000 excitonic emission events, and up to three times more events with a large background emission. To make a autocorrelation histogram the exciton emission times are compared and each time differences add one to the appropriate bin in the histogram. The relative position of the histogram bins are chosen so that the middle bin is centered around time difference zero. Finally, the histogram is normalized to one by using the bins that are sufficient far away from time difference zero, to be unaffected by the dip in the histogram.

\subsection{Simulated effect of background emission}

The background emission has a deteriorating effect on $g^{2}(0)$ because these background photons that start/stop the timing device originates from another source (i.e. not the QD) and since this emission in general is uncorrelated with the desired emission (and no single photon emitter) it emits photons at all time intervals. The deterioration of the histogram by an increased background emission compared to the signal drives the $g^{2}(0) \rightarrow 1$. An important parameter in this context is the $\rho$-value (see figure 3.2) that is defined in section 3.1.1. This parameter can vary between 0 and 1 , there is only signal (no background emission) for $\rho=1$ and only background emission for $\rho=0$. Simulations of the effect of different $\rho$ values on autocorrelation histograms for excitonic emission have been made. In figure 5.1a-d, simulations are seen for $\rho$-values decreasing from 1 to 0.33 resulting in a successive 

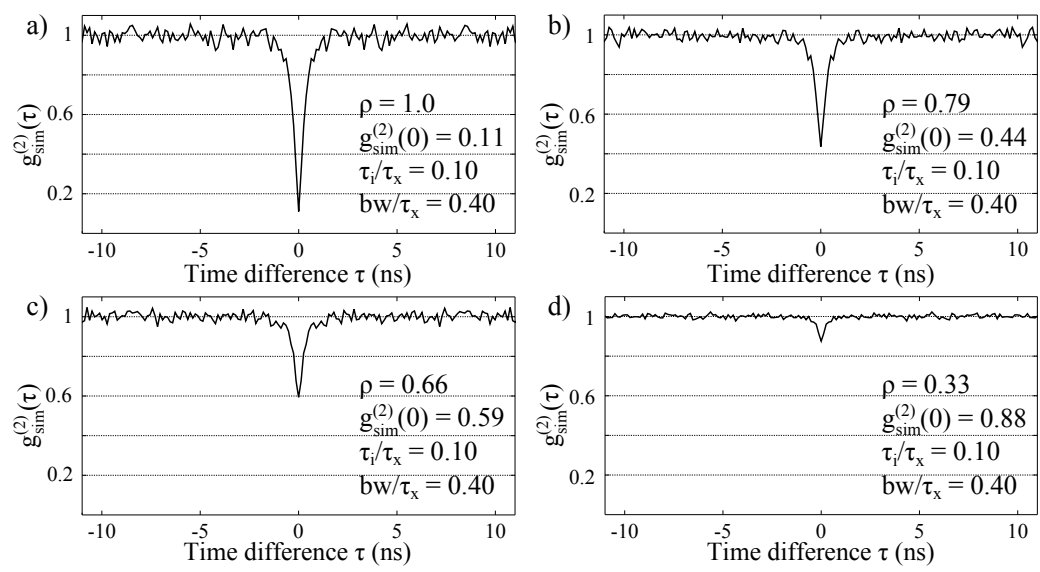

Figure 5.1: a-d) Simulations of autocorrelation measurements of an emission from an exciton with $\tau_{x}=0.32 \mathrm{~ns}, \tau_{i}=0.032 \mathrm{~ns}$ and the bin width $b w=0.128 \mathrm{~ns}$ for different $\rho$ values in the range of 1.0 to 0.33 and the effect on the $g_{\text {sim }}^{2}(\tau)$ value.

increase of $g_{\text {sim }}^{2}(0)$ from 0.11 to 0.88 . The residual value of $g_{\text {sim }}^{2}(0)=0.11$ $(>0)$ for $\rho=1$ are due to the finite values of the instrument response function $\left(\tau_{i}=0.032 \mathrm{~ns}\right)$ and the bin width $(b w=0.128 \mathrm{~ns})$ relative to the simulated exciton life time $\left(\tau_{x}=0.32 \mathrm{~ns}\right)$.

\subsection{Simulated effect of instrument time re- sponse}

The time measurements in TCSPS have high accuracy but nevertheless they are unideal and give a statistical spreading of the measured times. This statistical spread of the measured times causes a smoothing of the dip of the measured $g^{(2)}(\tau)$ histogram. Especially the value at $g^{(2)}(0)$ will be affected and pushed towards 1 . In mathematical terms $g^{(2)}(\tau)$ is convoluted with the instrument time response function of time spread $\tau_{i}$ (see equation 2 in Paper I). If $\tau_{i}$ is much faster than the characteristic anti-bunching time, $\tau_{c}$, of the measured emission, this will have negligible effect on the measured histogram, but for $\tau_{i}$ comparable to and larger than $\tau_{c}$ an increasingly severe deterioration of the $g^{(2)}(0)$ value will occur. This is clearly seen in the four 

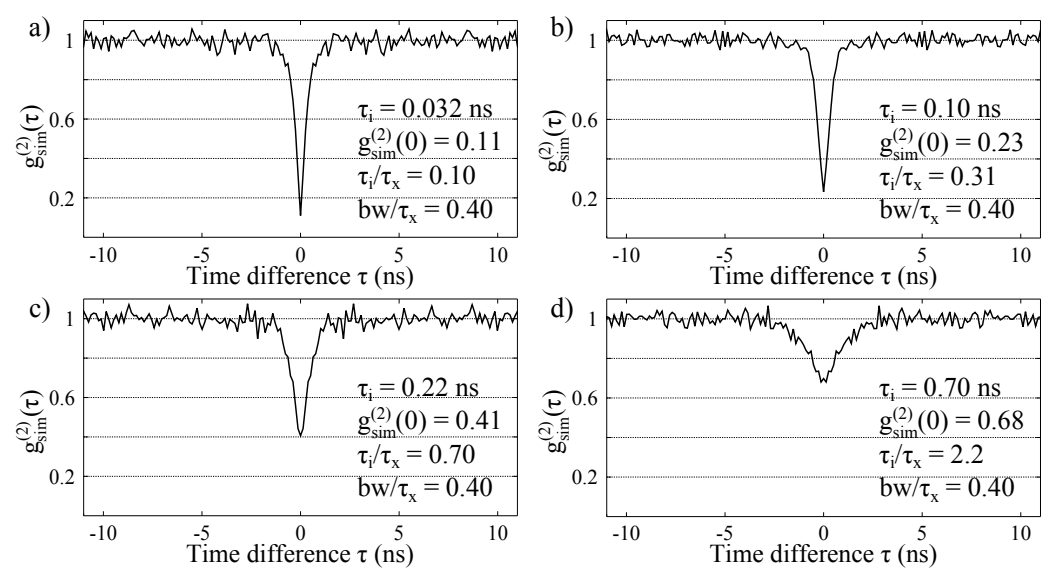

Figure 5.2: a-d) Simulations of the effect of different $\tau_{i}$ values on the autocorrelation measurements of an emission from an exciton with $\tau_{x}=0.32 \mathrm{~ns}, \rho=1.0$ and $b w=0.128 \mathrm{~ns}$ and the effect on the $g_{\text {sim }}^{(2)}(\tau)$ value.

simulations with $\tau_{i} / \tau_{x}$ values varying from 0.10 to 2.2 which gives a smaller and wider dip (figure $5.2 \mathrm{a}$-d) with the $g_{s i m}^{(2)}(0)$ value increasing from 0.11 to 0.68 .

\subsection{Simulated effect of histogram bin width}

Events with $\tau$ in a certain (small) time interval are placed in the same bin of the histogram. For the equipment used in this work, the $b w$ of the histogram, could be set to values in the range from $b w=4$ ps to $b w=512$ ps. If the bin width is comparable to the characteristic anti-bunching time of the emission, the dip will be represented by just a few data points (histogram bins) and each data point will be the average over a relatively large part of the dip. Consequently, in an autocorrelation histogram, the $g_{\text {sim }}^{(2)}(0)$ value will increase and the measured dip will slightly broaden. This effect starts to be visible when the bin width is larger than approximately one tenth of the characteristic anti-bunching time. In the four simulations shown in figure $5.3 \mathrm{a}-\mathrm{d}$, where different $b w$ but the same $\tau_{i}=0.032 \mathrm{~ns}, \tau_{x}=0.32 \mathrm{~ns}$ and $\rho=1.0$ are used, the increased $g_{\text {sim }}^{(2)}(0)$ value and slightly broadened dip 

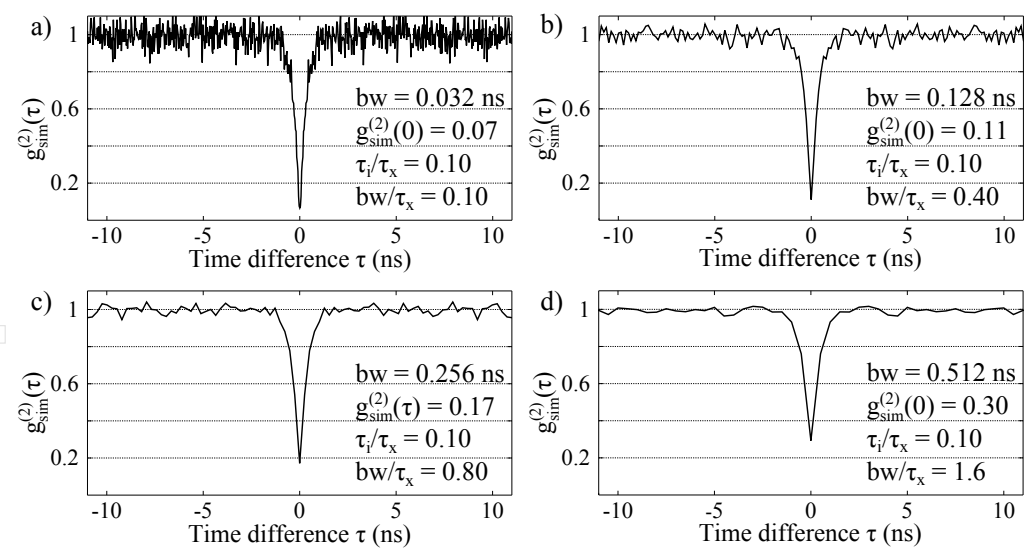

Figure 5.3: a-d) Simulations of autocorrelation measurements of an emission from an exciton with $\tau_{x}=0.32 \mathrm{~ns}, \rho=1.0$ and $\tau_{i}=0.032 \mathrm{~ns}$ for different bin width $(b w)$ and the effect on the $g^{(2)}(\tau)$ value.

is seen. The remnant value of $g_{\text {sim }}^{(2)}(0)=0.07$ in figure $5.3 \mathrm{a}$, is due to $\tau_{i}$.

\subsection{Combined effect of $b w, \tau_{i}$ and $\rho$ on the $g^{(2)}(0)$-value}

In a real measurement there is in general a combined contribution to $g^{(2)}(0)$ from the $b w, \tau_{i}$ and $\rho$. To give a more complete picture of the influences, simulations with different values of the parameters $\tau_{i} / \tau_{x}$ and $b w / \tau_{x}$ have been made for different values of $\rho$ for the excitonic emission. The $g_{\text {sim }}^{(2)}(0)$ value versus $\rho$ are plotted for a few values of the parameters in figure 5.4. From the figure it is clear that when $\tau_{i} / \tau_{x}$ is large, the improvement of $g_{s i m}^{(2)}(0)$ by a smaller bin width is minimal. To have a small value of $g_{s i m}^{(2)}(0)$ the background has to be low ( $\rho$ close to 1 ) and the $\tau_{i}$ and $b w$ values have to be substantially shorter than the lifetime. This requires high quality samples with high emission intensities and fast SPD detectors. 


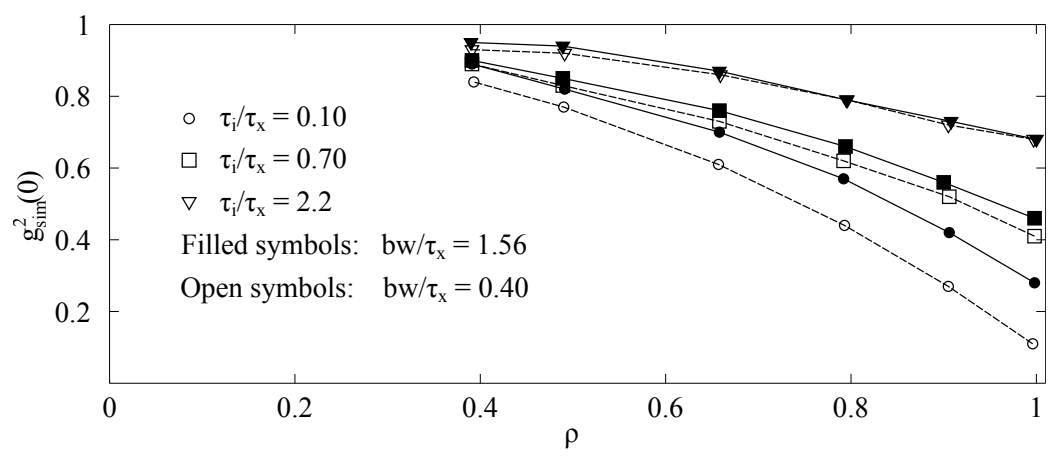

Figure 5.4: Extracted $g_{\text {sim }}^{(2)}(0)$ values, from simulations, of autocorrelated excitonic emission plotted against $\rho$ for different $\tau_{i} / \tau_{x}$ and $b w / \tau_{x}$ values. The lines are guidance for the eye. 


\section{Chapter 6}

\section{Bibliography}

[1] L. Badash, "The completeness of nineteenth-century science," Isis, vol. 63, no. 1, pp. pp. 48-58, 1972.

[2] C. Kittel, Introduction to solid state physics. New York: Wiley, 1986.

[3] H. Grimmeiss and H. Koelmans, "Uber die kantenemission und andere emissionen des GaN," Z. f. Naturforsch, vol. 14a, p. 264, 1959.

[4] N. Grandjean and M. Ilegems, "Visible InGaN/GaN quantum-dot materials and devices," Proceedings of the IEEE, vol. 95, pp. 1853-1865, sep 2007.

[5] H. Amano, N. Sawaki, I. Akasaki, and Y. Toyoda, "Metalorganic vapor phase epitaxial growth of a high quality GaN film using an AlN buffer layer.," Applied Physics Letters, vol. 48, no. 5, p. 353, 1986.

[6] S. Nakamura, T. Mukai, and M. Senoh, "Candelaclass highbrightness InGaN/AlGaN doubleheterostructure bluelightemitting diodes," Applied Physics Letters, vol. 64, no. 13, pp. 1687-1689, 1994.

[7] Nobelprize.org. Nobel Media AB 2014, "The nobel prize in physics 2014," Jan 5 2015. http://www.nobelprize.org/nobel prizes/physics/laureates/2014/.

[8] M. D. Eisaman, J. Fan, A. Migdall, and S. V. Polyakov, "Invited review article: Single-photon sources and detectors.," Review of Scientific Instruments, vol. 82, no. 7, p. 071101, 2011. 
[9] Quantum cryptography: Public-key distribution and coin tossing, Proceedings of IEEE International Conference on Computers, Systems and signal Processing, (Bangalore, India), Dec 10-12 1988.

[10] N. Gisin, G. Ribordy, W. Tittel, and H. Zbinden, "Quantum cryptography," Rev. Mod. Phys., vol. 74, pp. 145-195, Mar. 2002.

[11] P. Michler, A. Kiraz, C. Becher, W. V. Schoenfeld, P. M. Petroff, L. Zhang, E. Hu, and A. Imamoglu, "A quantum dot single-photon turnstile device," Science, vol. 290, no. 5500, pp. 2282-2285, 2000.

[12] V. Davydov, A. Klochikhin, R. Seisyan, V. Emtsev, S. Ivanov, F. Bechstedt, J. Furthmüller, H. Harima, A. Mudryi, J. Aderhold, O. Semchinova, and J. Graul, "Absorption and emission of hexagonal InN. evidence of narrow fundamental band gap," Physica status solidi (b), vol. 229, no. 3, pp. R1-R3, 2002.

[13] M. E. Levinshtein, Properties of advanced semiconductor materials : GaN, AlN, InN, BN, SiC, SiGe. New York: Wiley, 2001.

[14] I. Vurgaftman and J. R. Meyer, "Band parameters for nitrogencontaining semiconductors," Journal of Applied Physics, vol. 94, no. 6, pp. 3675-3696, 2003.

[15] O. Ambacher, "Growth and applications of group III-nitrides," Journal of Physics D: Applied Physics, vol. 31, no. 20, p. 2653, 1998.

[16] S. C. Jain, M. Willander, J. Narayan, and R. V. Overstraeten, "Iii-nitrides: Growth, characterization, and properties," Journal of Applied Physics, vol. 87, no. 3, pp. 965-1006, 2000.

[17] B. Lounis and M. Orrit, "Single-photon sources," Reports on Progress in Physics, vol. 68, no. 5, p. 1129, 2005.

[18] M. Winkelnkemper, A. Schliwa, and D. Bimberg, "Interrelation of structural and electronic properties in $\operatorname{In}_{x} \mathrm{Ga}_{1-x} \mathrm{~N} / \mathrm{GaN}$ quantum dots using an eight-band k center dot p model," Physical Review B, vol. 74, Oct 2006 .

[19] L. Zhang, C.-H. Teng, T. A. Hill, L.-K. Lee, P.-C. Ku, and H. Deng, "Single photon emission from site-controlled InGaN/GaN quantum dots," Applied Physics Letters, vol. 103, no. 19, p. 192114, 2013. 
[20] S. Deshpande and P. Bhattacharya, "An electrically driven quantum dot-in-nanowire visible single photon source operating up to 150k," Applied Physics Letters, vol. 103, no. 24, p. 241117, 2013.

[21] M. J. Holmes, K. Choi, S. Kako, M. Arita, and Y. Arakawa, "Roomtemperature triggered single photon emission from a III-nitride sitecontrolled nanowire quantum dot," Nano Letters, vol. 14, no. 2, pp. 982 986, 2014.

[22] G. Gilliland, "Photoluminescence spectroscopy of crystalline semiconductors," Materials Science and Engineering: R: Reports, vol. 18, no. 3-6, pp. 99 - 399, 1997.

[23] A. Gustafsson, M.-E. Pistol, L. Montelius, and L. Samuelson, "Local probe techniques for luminescence studies of low-dimensional semiconductor structures," Journal of Applied Physics, vol. 84, no. 4, pp. 1715$1775,1998$.

[24] S. G. Lipson, Optical physics. Cambridge New York, NY, USA: Cambridge University Press, 1995.

[25] R. Hanbury Brown and R. Q. Twiss, "Correlation between Photons in two Coherent Beams of Light," Nature, vol. 177, pp. 27-29, Jan. 1956.

[26] R. Hanbury Brown and R. Q. Twiss, "A test of a new type of stellar interferometer on sirius," Nature, vol. 178, pp. 1046-1048, Nov. 1956.

[27] R. Hanbury Brown and R. Q. Twiss, "The question of correlation between photons in coherent light rays," Nature, vol. 178, pp. 1447-1448, Dec. 1956.

[28] R. H. Brown, J. Davis, and L. R. Allen, "The stellar interferometer at Narrabri observatory - i: A description of the instrument and the observational procedure," Monthly Notices of the Royal Astronomical Society, vol. 137, no. 4, pp. 375-392, 1967.

[29] R. H. Brown, J. Davis, L. R. Allen, and J. M. Rome, "The stellar interferometer at Narrabri observatory - ii: The angular diameters of 15 stars," Monthly Notices of the Royal Astronomical Society, vol. 137, no. 4, pp. 393-417, 1967. 
[30] S. Trippe, J.-Y. Kim, B. Lee, C. Choi, J. Oh, T. Lee, S.-C. Yoon, M. Im, and Y.-S. Park, "Optical Multi-Channel Intensity Interferometry - or: How To Resolve O-Stars in the Magellanic Clouds," ArXiv e-prints, Oct. 2014 .

[31] G. Baym, "The physics of Hanbury Brown-Twiss intensity interferometry: From stars to nuclear collisions," Acta Physica Polonica B, vol. 29, pp. 1839-1884, July 1998. XXXVII Cracow School of Theoretical Physics, Zakopane, Poland, May 30-Jun 10, 1997.

[32] G. A. Rebka and R. V. Pound, "Time-Correlated Photons," Nature, vol. 180, pp. 1035-1036, Nov. 1957.

[33] C. C. Gerry and K. P. L., Introductory quantum optics. Cambridge, UK New York: Cambridge University Press, 2005.

[34] R. Loudon, The quantum theory of light. Oxford New York: Oxford University Press, 2000.

[35] H. Kimble, M. Dagenais, and L. Mandel, "Photon anti-bunching in resonance fluorescence," Physical Review Letters, vol. 39, no. 11, pp. 691$695,1977$.

[36] B. Lounis, H. Bechtel, D. Gerion, P. Alivisatos, and W. Moerner, "Photon antibunching in single CdSe/ZnS quantum dot fluorescence," Chemical Physics Letters, vol. 329, no. 5-6, pp. 399 - 404, 2000.

[37] C. Foellmi, "Intensity interferometry and the second-order correlation function $\mathrm{g}^{(2)}$ in astrophysics," Astronomy \& Astrophysics, vol. 507, pp. 1719-1727, Dec. 2009.

[38] M. Fox, Quantum optics : an introduction. Oxford New York: Oxford University Press, 2006.

[39] R. Glauber, Quantum theory of optical coherence : selected papers and lectures. Weinheim: Wiley-VCH, 2007.

[40] Nobelprize.org. Nobel Media AB 2014, "The nobel prize in physics 2005," Jan 6 2015. http://www.nobelprize.org/nobel prizes/physics/laureates/2005/. 
[41] R. Verberk and M. Orrit, "Photon statistics in the fluorescence of single molecules and nanocrystals: Correlation functions versus distributions of on- and off-times," The Journal of Chemical Physics, vol. 119, no. 4, pp. 2214-2222, 2003.

[42] D. Dufåker, K. F. Karlsson, L. O. Mereni, V. Dimastrodonato, G. Juska, E. Pelucchi, and P. O. Holtz, "Quantum dot asymmetry and the nature of excited hole states probed by the doubly positively charged exciton $X^{2+}, "$ Phys. Rev. B, vol. 88, p. 045321, Jul 2013.

[43] H. Nakajima, H. Kumano, H. Iijima, and I. Suemune, "Anomalous dip observed in intensity autocorrelation function as an inherent nature of single-photon emitters.," Applied Physics Letters, vol. 101, no. 16, p. $161107,2012$.

[44] B. Lounis and W. Moerner, "Single photons on demand from a single molecule at room temperature," Nature, vol. 407, pp. 491-493, Sept. 2000 .

[45] PicoQuant, "Complementary information," Dec 12014. http://www.picoquant.com/products/category/photoncounting-detectors/pma-series-photomultiplier-detector-assembly http://www.picoquant.com/products/category/photon-countingdetectors/tau-spad-single-photon-counting-module.

[46] G. Blom, Sannolikhetsteori och statistikteori med tillämpningar. Lund: Studentlitt, 1980. 



\section{Papers}

The articles associated with this thesis have been removed for copyright reasons. For more details about these see:

http://urn.kb.se/resolve?urn=urn:nbn:se:liu:diva-113348 


\section{Studies in Science and Technology Education \\ ISSN 1652-5051 \\ fontD}

14. Christel Persson (2008): Sfärernas symfoni i förändring? Lärande i miljö för hållbar utveckling med naturvetenskaplig utgångspunkt. En longitudinell studie i grundskolans tidigare årskurser. (Doctoral Dissertation) Linköping University

15. Eva Davidsson (2008): Different Images of Science - a study of how science is constituted in exhibitions. ISBN: 978-91-977100-1-5 (Doctoral Dissertation) Malmö University

16. Magnus Hultén (2008): Naturens kanon. Formering och förändring av innehållet i folkskolans och grundskolans naturvetenskap 1842-2007. ISBN: 978-91-7155-612-7 (Doctoral Dissertation) Stockholm University

17. Lars-Erik Björklund (2008): Från Novis till Expert: Förtrogenhetskunskap i kognitiv och didaktisk belysning. (Doctoral Dissertation) Linköping University.

18. Anders Jönsson (2008): Educative assessment for/of teacher competency. A study of assessment and learning in the "Interactive examination" for student teachers. ISBN: 978-91-977100-3-9 (Doctoral Dissertation) Malmö University

19. Pernilla Nilsson (2008): Learning to teach and teaching to learn - primary science student teachers' complex journey from learners to teachers. (Doctoral Dissertation) Linköping University

20. Carl-Johan Rundgren (2008): VISUAL THINKING, VISUAL SPEECH - a Semiotic Perspective on Meaning-Making in Molecular Life Science. (Doctoral Dissertation) Linköping University

21. Per Sund (2008): Att urskilja selektiva traditioner i miljöundervisningens socialisationsinnehåll - implikationer för undervisning för hållbar utveckling. ISBN: 978-91-85485-88-8 (Doctoral Dissertation) Mälardalen University

22. Susanne Engström (2008): Fysiken spelar roll! I undervisning om hållbara energisystem - fokus på gymnasiekursen Fysik A. ISBN: 978-91-85485-96-3 (Licentiate thesis) Mälardalen University

23. Britt Jakobsson (2008): Learning science through aesthetic experience in elementary school science. Aesthetic judgement, metaphor and art. ISBN: 978-91-7155-654-7. (Doctoral Dissertation) Stockholm university

24. Gunilla Gunnarsson (2008): Den laborativa klassrumsverksamhetens interaktioner En studie om vilket meningsskapande år 7-elever kan erbjudas i möten med den laborativa verksamhetens instruktioner, artefakter och språk inom elementär ellära, samt om lärares didaktiska handlingsmönster i dessa möten. (Doctoral Dissertation) Linköping University

25. Pernilla Granklint Enochson (2008): Elevernas föreställningar om kroppens organ och kroppens hälsa utifrån ett skolsammanhang. (Licentiate thesis) Linköping University

26. Maria Åström (2008): Defining Integrated Science Education and putting it to test (Doctoral Dissertation) Linköping University

27. Niklas Gericke (2009): Science versus School-science. Multiple models in genetics The depiction of gene function in upper secondary textbooks and its influence on students' understanding. ISBN 978-91-7063-205-1 (Doctoral Dissertation) Karlstad University 


\section{Studies in Science and Technology Education \\ ISSN 1652-5051 \\ FontD}

28. Per Högström (2009): Laborativt arbete i grundskolans senare år - lärares mål och hur de implementeras. ISBN 978-91-7264-755-8 (Doctoral Dissertation) Umeå University

29. Annette Johnsson (2009): Dialogues on the Net. Power structures in asynchronous discussions in the context of a web based teacher training course. ISBN 978-91977100-9-1 (Doctoral Dissertation) Malmö University

30. Elisabet M. Nilsson (2010): Simulated "real" worlds: Actions mediated through computer game play in science education. ISBN 978-91-86295-02-8 (Doctoral Dissertation) Malmö University

31. Lise-Lotte Österlund (2010): Redox models in chemistry: A depiction of the conceptions held by upper secondary school students of redox reactions. ISBN 97891-7459-053-1 (Doctoral Dissertation) Umeå University

32. Claes Klasander (2010): Talet om tekniska system - förväntningar, traditioner och skolverkligheter. ISBN 978-91-7393-332-2 (Doctoral Dissertation) Linköping University

33. Maria Svensson (2011): Att urskilja tekniska system - didaktiska dimensioner i grundskolan. ISBN 978-91-7393-250-9 (Doctoral Dissertation) Linköping University

34. Nina Christenson (2011): Knowledge, Value and Personal experience - Upper secondary students' use of supporting reasons when arguing socioscientific issues. ISBN 978-91-7063-340-9 (Licentiate thesis) Karlstad University

35. Tor Nilsson (2011): Kemistudenters föreställningar om entalpi och relaterade begrepp. ISBN 978-91-7485-002-4 (Doctoral Dissertation) Mälardalen University

36. Kristina Andersson (2011): Lärare för förändring - att synliggöra och utmana föreställningar om naturvetenskap och genus. ISBN 978-91-7393-222-6 (Doctoral Dissertation) Linköping University

37. Peter Frejd (2011): Mathematical modelling in upper secondary school in Sweden An exploratory study. ISBN: 978-91-7393-223-3 (Licentiate thesis) Linköping University

38. Daniel Dufåker (2011): Spectroscopy studies of few particle effects in pyramidal quantum dots. ISBN 978-91-7393-179-3 (Licentiate thesis) Linköping University

39. Auli Arvola Orlander (2011): Med kroppen som insats: Diskursiva spänningsfält i biologiundervisningen på högstadiet. ISBN 978-91-7447-258-5 (Doctoral Dissertation) Stockholm University

40. Karin Stolpe (2011): Att uppmärksamma det väsentliga. Lärares ämnesdidaktiska förmågor ur ett interaktionskognitivt perspektiv. ISBN 978-91-7393-169-4 (Doctoral Dissertation) Linköping University

41. Anna-Karin Westman (2011) Samtal om begreppskartor - en väg till ökad förståelse. ISBN 978-91-86694-43-2 (Licentiate thesis) Mid Sweden University

42. Susanne Engström (2011) Att vördsamt värdesätta eller tryggt trotsa. Gymnasiefysiken, undervisningstraditioner och fysiklärares olika strategier för energiundervisning. ISBN 978-91-7485-011-6 (Doctoral Dissertation) Mälardalen University

43. Lena Adolfsson (2011) Attityder till naturvetenskap. Förändringar av flickors och pojkars attityder till biologi, fysik och kemi 1995 till 2007. ISBN 978-91-7459-233-7 (Licentiate thesis) Umeå University 


\section{Studies in Science and Technology Education \\ ISSN 1652-5051 \\ fontD}

44. Anna Lundberg (2011) Proportionalitetsbegreppet i den svenska gymnasiematematiken - en studie om läromedel och nationella prov. ISBN 978-91-7393-132-8 (Licentiate thesis) Linköping University

45. Sanela Mehanovic (2011) The potential and challenges of the use of dynamic software in upper secondary Mathematics. Students' and teachers' work with integrals in GeoGebra based environments. ISBN 978-91-7393-127-4 (Licentiate thesis) Linköping University

46. Semir Becevic (2011) Klassrumsbedömning i matematik på gymnasieskolans nivå. ISBN 978-91-7393-091-8 (Licentiate thesis) Linköping University

47. Veronica Flodin (2011) Epistemisk drift - genbegreppets variationer i några av forskningens och undervisningens texter i biologi. ISBN 978-91-9795-161-6 (Licentiate thesis) Stockholm University

48. Carola Borg (2011) Utbildning för hållbar utveckling ur ett lärarperspektiv Ämnesbundna skillnader i gymnasieskolan. ISBN 978-91-7063-377-5 (Licentiate thesis) Karlstad University

49. Mats Lundström (2011) Decision-making in health issues: Teenagers' use of science and other discourses. ISBN 978-91-86295-15-8 (Doctoral Dissertation) Malmö University

50. Magnus Oscarsson (2012) Viktigt, men inget för mig. Ungdomars identitetsbygge och attityd till naturvetenskap. ISBN: 978-91-7519-988-7 (Doctoral Dissertation) Linköping University

51. Pernilla Granklint Enochson (2012) Om organisation och funktion av människokroppens organsystem - analys av elevsvar från Sverige och Sydafrika. ISBN 978-91-7519-960-3 (Doctoral Dissertation) Linköping University

52. Mari Stadig Degerman (2012) Att hantera cellmetabolismens komplexitet Meningsskapande genom visualisering och metaforer. ISBN 978-01-7519-954-2 (Doctoral Dissertation) Linköping University

53. Anna-Lena Göransson (2012) The Alzheimer $A^{2}$ peptide: Identification of Properties Distinctive for Toxic Prefibrillar Species. ISBN 978-91-7519-930-6 (Licentiate thesis) Linköping University

54. Madelen Bodin (2012) Computational problem solving in university physics education - Students' beliefs, knowledge, and motivation. ISBN 978-91-7459-398-3 (Doctoral Dissertation) Umeå University

55. Lena Aretorn (2012) Mathematics in the Swedish Upper Secondary School Electricity Program: A study of teacher knowledge. ISBN 978-91-7459-429-4 (Licentiate thesis) Umeå University

56. Anders Jidesjö (2012) En problematisering av ungdomars intresse för naturvetenskap och teknik i skola och samhälle - Innehåll, medierna och utbildningens funktion. ISBN 978-91-7519-873-6 (Doctoral Dissertation) Linköping University

57. Thomas Lundblad (2012) Simulerad verklighet i gymnasieskolans fysik: en designstudie om en augmented reality simulering med socio-naturvetenskapligt innehåll. ISBN 978-91-7519-854-5 (Licentiate thesis) Linköping University

58. Annie-Maj Johansson (2012) Undersökande arbetssätt i NO-undervisningen i grundskolans tidigare årskurser. ISBN 978-91-7447-552-4 (Doctoral Dissertation) Stockholm University 
Studies in Science and Technology Education

ISSN 1652-5051

\section{fontD}

59. Anna Jobér (2012) Social Class in Science Class. ISBN 978-91-86295-31-8 (Doctoral Dissertation) Malmö University

60. Jesper Haglund (2012) Analogical reasoning in science education - connections to semantics and scientific modeling in thermodynamics. ISBN 978-91-7519-773-9

(Doctoral Dissertation) Linköping University

61. Fredrik Jeppsson (2012) Adopting a cognitive semantic approach to understand thermodynamics within science education. ISBN 978-91-7519-765-4 (Doctoral Dissertation) Linköping University

62. Maria Petersson (2012) Lärares beskrivningar av evolution som undervisningsinnehåll i biologi på gymnasiet.ISBN 978-91-7063-453-6 (Doctoral Dissertation) Karlstad University

63. Henrik Carlsson (2012) Undervisningsform, klassrumsnormer och matematiska förmågor. En studie av ett lokalt undervisningsförsök för elever med intresse och fallenhet för matematik. ISBN 978-91-86983-89-5 (Licentiate thesis) Linnaeus University)

64. Anna Bergqvist (2012) Models of Chemical Bonding. Representations Used in School Textbooks and by Teachers and their Relation to Students' Understanding. ISBN 97891-7063-463-5 (Licentiate thesis) Karlstad University

65. Nina Kilbrink (2013) Lära för framtiden: Transfer i teknisk yrkesutbildning. ISBN 978-91-7063-478-9 (Doctoral Dissertation) Karlstad University

66. Caroline Larsson (2013) Experiencing Molecular Processes. The Role of Representations for Students' Conceptual Understanding. ISBN 978-91-7519-607-7 (Doctoral Dissertation) Linköping University

67. Anna-Karin Carstensen (2013) Connect Modelling Learning to Facilitate Linking Models and the Real World through Labwork in Electric Circuit Courses for Engineering Students ISBN 978-91-7519-562-9 (Doctoral Dissertation) Linköping University

68. Konferensproceeding: 10-year Anniversary Meeting with the Scientific Committee

69. Marie Bergholm (2014) Gymnasieelevers kommunikativa strategier i matematikklassrummet. En fallstudie av ett smågruppsarbete om derivata ISBN 97891-7519-306-9 (Licentiate thesis) Linköping University

70. Ingrid Lundh (2014) Undervisa Naturvetenskap genom Inquiry - En studie av två högstadielärare. ISBN 978-91-7519-285-7 (Licentiate thesis) Linköping University

71. Nils Boman (2014) Personality traits in fish - implications for invasion biology ISBN:978-91-7601-097-6 (Licentiate thesis) Umeå University

72. Torodd Lunde (2014) När läroplan och tradition möts - lärarfortbildning och syften med undersökande aktiviteter inom den laborativa NO-undervisningen i grundskolans senare del. ISBN: 978-91-7063-577-9 (Licentiate thesis) Karlstad University

73. Martin Eriksson (2014) Att ta ställning - gymnasieelevers argumentation och beslutsfattande om sociovetenskapliga dilemman. ISBN 978-91-7063-588-5 (Licentiate thesis), Karlstad University

74. Annalena Holm (2014) Mathematics Communication within the Frame of Supplemental Instruction. Identifying Learning Conditions. ISBN 978-91-7623-112-8 (Licentiate thesis) Lund University 
Studies in Science and Technology Education

ISSN 1652-5051

fonkd

75. Daniel Olsson (2014) Young people's 'Sustainability Consciousness' - Effects of ESD implementation in Swedish schools. ISBN 978-91-7063-594-6. (Licentiate thesis) Karlstad University

76. Marlene Sjöberg (2014) Möjligheter I kollegiala samtal om NO-undervisning och bedömning. https://gupea.ub.gu.se/handle/2077/24063 (Licentiate thesis) Gothenburg University.

77. Teresa Berglund (2014) Student 'Sustainability Consciousness' and Decision-Making on Sustainability Dilemmas. Investigating effects of implementing education for sustainable development in Swedish upper secondary schools. ISBN 978-91-7063599-1 (Licentiate thesis) Karlstad University

78. Elisabet Mellroth (2014) High achiever! Always a high achiever? A comparison of student achievements on mathematical tests with different aims and goals. ISBN 97891-7063-607-3 (Licentiate thesis) Karlstad University

79. Jenny Green (2014) Elevers användande av formativ återkoppling i matematik. ISBN 978-91-7519-164-5 (Licentiate thesis) Linköping University

80. Klara Kerekes (2014) Matematikundervisning om växande geometriska mönster-en variationsteoretisk studie om hur lärare behandlar ett matematiskt innehållI. ISBN: (Licentiate thesis) Linköping University

81. Cecilia Axell (2015) Barnlitteraturens tekniklandskap: en didaktisk vandring från Nils Holgersson till Pettson och Findus. ISBN 978-91-7519-227-7 (Doctoral Dissertation) Linköping University.

82. Jan Forsgren (2015) Synthesis and characterization of catalysts for hydrogen production from water ISBN 978-91-7601-206-2.(Licentiate thesis) Umeå University

83. Maria Eriksson (2015) Att kommunicera naturvetenskap i nationella prov: En studie med andraspråksperspektiv. ISBN 978-91-7519-138-6 (Licentiate thesis) Linköping University

84. Tomas Jemsson (2015) Time correlated single photon spectroscopy on pyramidal quantum dots. ISBN 978-91-7519-143-0 (Licentiate thesis) Linköping University 